TITLE:

\title{
Unprecedented formation of binuclear copper(II) complex with a perylene derived ligand by the oxidative reaction
}

\section{$\operatorname{AUTHOR}(\mathrm{S}):$}

Hagiwara, Jun; Shimazaki, Yuichi; Saito, Gunzi

\section{CITATION:}

Hagiwara, Jun ...[et al]. Unprecedented formation of binuclear copper(II) complex with a perylene derived ligand by the oxidative reaction. Inorganica Chimica Acta 2010, 363(13): 3178-3185

ISSUE DATE:

2010-10-25

URL:

http://hdl.handle.net/2433/135367

\section{RIGHT:}

(c) 2010 Elsevier B.V.; この論文は出版社版でありません。引用の際には 出版社版をご確認ご利用ください。; This is not the published version. Please cite only the published version. 


\section{Unprecedented formation of binuclear copper(II) complex with a perylene derived ligand by the oxidative reaction}

Jun Hagiwara*a, Yuichi Shimazaki ${ }^{\mathrm{b}}$, and Gunzi Saito ${ }^{\mathrm{c}}$

${ }^{a}$ Division of Chemistry, Graduate School of Science, Kyoto University, Kitashirakawa Oiwake-cho, Sakyo-ku, Kyoto 606-8502, Japan

${ }^{\mathrm{b}}$ College of Science, Ibaraki University, Bunkyo, Mito, 310-8512, Japan

${ }^{\mathrm{b}}$ Frontier Research Center for Applied Atomic Sciences, Ibaraki University, , Bunkyo, Mito, 310-8512, Japan

${ }^{c}$ Research Institute, Meijo University, Shiogamaguchi 1-501 Tempaku, Nagoya 468-8502, Japan

Received

* Corresponding author. Tel: $+81-75-753-4062$

E-mail address: hagiwara@kuchem.kyoto-u.ac.jp 


\section{Abstract}

A

new

perylene-pendent

tridentate

ligand,

$N$-(3-perylenylmethyl)- $N, N$-bis(2-pyridylmethyl)amine (perbpa) $\mathbf{1}$ and its $\mathrm{Cu}(\mathrm{II})$ complex, $\quad\left[\mathrm{Cu}(\right.$ perbpa $\left.) \mathrm{Cl}_{2}\right]$ (2) were prepared and structurally characterized by the $\mathrm{X}$-ray diffraction method. In the packing structure of ligand 1, perylene groups were aggregated to form a $\pi-\pi$ stacked layer of dimerized pelylene moieties similar to the packing of pristine perylene. This result suggests both that the $\pi-\pi$ interactions among the perylene moieties predominate for the arrangement of perbpa molecules in the crystal and that this ligand is a good candidate for constructing electron conducting path. A complex 2 was prepared from the ligand 1 and a copper(II) chloride dehydrate. 2 had a mononuclear and 5-coordinate distorted square pyramidal structure with a perbpa and two coordinated chloride ions. The chemical oxidation of 2 by iodine resulted in the unprecedented binuclear $\mathrm{Cu}(\mathrm{II})$ species, $\left[\mathrm{Cu}_{2}(\mu-\mathrm{Cl})_{2}(\text { perbpa })_{2}\right]\left(\mathrm{I}_{3}\right)_{2}, 3 \cdot\left(\mathrm{I}_{3}\right)_{2}$. An X-ray crystal structure analysis of $\mathbf{3} \cdot\left(\mathrm{I}_{3}\right)_{2}$ revealed the binuclear structure bridged by the chloride ions. A temperature dependent magnetic susceptibility measurement of $\mathbf{3}$ showed a weak ferromagnetic exchange interaction with $S=1$ ground state, $g=2.12$ and $J=+1.17 \mathrm{~cm}^{-1}$, based on $\boldsymbol{H}=-2 J S_{1} \cdot S_{2}$. The UV-vis absorption and the EPR spectra of $\mathbf{3}$ showed that the perylene groups are not oxidized. These results indicate a couple of $\mathrm{Cu}$ (II) constructed $S=1$ ground state with intermolecular ferromagnetic interaction. The electrochemical study suggested that the crystallization of $\mathbf{3} \cdot\left(\mathrm{I}_{3}\right)_{2}$ was initiated by the oxidation of the $N, N$-bis-(2-pyridylmethyl)amino (bpa) groups of 2 by $\mathrm{I}_{2}$.

Keywords: binuclear copper(II) complex; perylene based ligand; chemical oxidation; magnetic property; electrochemical property. 


\section{Introduction}

Molecular-based system with a synergetic interaction between magnetic and transport properties has been extensively studied in the past two decades because such a system is fascinating from a theoretical [1, 2] and phenomenological [3] point of view [4]. In order to construct such a system, tetrathiafulvalene (TTF, Scheme 1) derivatives with coordinating groups have been developed [5]. We previously reported that the reaction of TTF-pendent bis(pyridylmethyl)amine (TTFbpa) (Scheme 1) with the Fe(III) ion gave an $\mathrm{Fe}$ (II) complex coordinated with oxidized TTF ligand [6]. Even though TTFbpa is a tridentate, flexible, and redox-active ligand, the conducting path of the stacked $\pi$-system was not formed due to the mismatch in size between the TTF group and the transition metal coordination centre. In order to resolve this mismatch, replacement of the TTF group by the larger $\pi$ donor may be required. With these points in mind, we investigated $\mathrm{Cu}$ (II) complexes of newly synthesized perylene-pendent bpa ligand (Scheme 1). Perylene has a large $\pi$-conjugated electronic system with moderate electron donating ability. The charge transfer complex of perylene and bromine is known as the first molecular-based conductor [7]. A Perylene-based radical ion and group 10 metal ion salts $(\mathrm{Ni}, \mathrm{Pd}$, and $\mathrm{Pt})$, (perylene $)_{2}\left[\mathrm{M}(\mathrm{mnt})_{2}\right]$ (mnt represents maleonitriledithiolate), have been reported as $\pi$-d coexisting and cooperating systems [8]. Herein we report the synthesis, X-ray crystal structure determination, and magnetic and spectroscopic characterizations of the mononuclear and binuclear $\mathrm{Cu}$ (II) complexes containing a new perylene-pendent-bpa ligand, perbpa (1).

\section{Experimental}

\subsection{Materials and methods}

Sodium cyanotrihydroborate was purchased from Wako Pure Chemical Industries. 2,2'-Dipicolylamine and tetra- $n$-buthylammonium triiodide $\left(n-\mathrm{Bu}_{4} \mathrm{NI}_{3}\right)$ were purchased from Tokyo Chemical Industry. Copper(II) chloride dihydrate, and iodine were purchaced from Nacalai tesque. 3-Perylenecarbaldehyde was prepared according to the literature [9]. All solvents were purified by conventional methods [10]. ${ }^{1} \mathrm{H}$ NMR spectra were recorded on a JEOL JNM-FX400 spectrometer operating at $400 \mathrm{MHz}$. Melting point was measured on a Yanaco MP-500D micro melting point apparatus and was not corrected. UV-vis spectra of solid samples using $\mathrm{KBr}$ disk method were recorded on a 
SHIMADZU UV-3100 spectrophotometer. UV-vis spectra of solutions were recorded on a JASCO V-670 spectrophotometer. The temperature dependence of static susceptibility measurements of the polycrystalline samples was carried out on a superconducting quantum interference device (SQUID) magnetometer of Quantum Design MPMSR2-XL from $2 \mathrm{~K}$ to $300 \mathrm{~K}$ at $0.1 \mathrm{~T}$. Magnetization data were corrected for sample folder and for diamagnetic contribution calculated from Pascal's constants [11]. Elecron paramagnetic resonance (EPR) spectra of the polycrystalline samples were recorded on a JEOL JES-TE200 X-band (9 GHz) ESR spectrometer equipped with a JEOL ES-CT470 cryostat from $4 \mathrm{~K}$ to $300 \mathrm{~K}$. EPR spectrum of dimethylformamide (DMF) frozen solution in $77 \mathrm{~K}$ was recorded on a JEOL JES-RE1X X-band spectrometer equipped with a standard low-temperature apparatus. Cyclic voltammetry $(\mathrm{CV})$ and differential pulse voltammetry (DPV) measurements were carried out on the DMF solution of 0.1 $\mathrm{M} n-\mathrm{Bu}_{4} \mathrm{NClO}_{4}$ vs. $\mathrm{Ag} / \mathrm{AgCl}$ by means of an ALS/chi electrochemical analyzer model $650 \mathrm{~A}$ at room temperature under nitrogen atmosphere. Voltammograms were recorded with a platinum disk and a platinum wire for working and counter electrodes, respectively. Sweeping velocity was $10 \mathrm{mV} \mathrm{s}^{-1}$.

\subsection{Synthesis of ligand, $N$-(3-perylenylmethyl)-N,N-bis(2-pyridylmethyl)amine (perbpa)} (1).

A 1,2-dichloroethane solution $(50 \mathrm{ml})$ of 3-perylenecarbaldehyde $(1.4 \mathrm{~g}, 5.0$ $\mathrm{mmol})$ and acetic acid $(1.0 \mathrm{ml})$ were added to an ethanol solution $(50 \mathrm{ml})$ of 2,2'-dipicolylamine (1.0 g, $5.0 \mathrm{mmol})$. To the mixture was added sodium cyanotrihydroborate $(90 \%, 0.36 \mathrm{~g}, 5.2 \mathrm{mmol})$. After the reaction mixture was refluxed for 2 hours under argon atmosphere, it was concentrated to dryness under a reduced pressure and acidified with $1 \mathrm{M} \mathrm{HCl}$ aqueous solution $(50 \mathrm{ml})$. The acidic solution was neutralized with saturated sodium hydrogen carbonate, and extracted with chloroform (2 $\times 50 \mathrm{ml})$. The combined organic layer was washed with brine $(100 \mathrm{ml})$, dried over anhydrous sodium sulfate, and evaporated to give red solid, which was purified by silica gel column chromatography (at first chloroform and successively chloroform/methanol $20 / 1(\mathrm{v} / \mathrm{v})$ ). The crude product (yellow powder) was recrystallized from benzene to give yellow platelets $(1.1 \mathrm{~g}, 48 \%) .{ }^{1} \mathrm{H} \mathrm{NMR}\left(\mathrm{CDCl}_{3}, \delta / \mathrm{ppm}\right.$ vs. TMS) 8.53 (m, 2H, py-H), $8.15(\mathrm{~m}, 4 \mathrm{H}$, py-H), $7.97(\mathrm{~d}, J=8.4 \mathrm{~Hz}, 1 \mathrm{H}$, per-H), $7.63(\mathrm{~m}, 5 \mathrm{H}$, per- $\mathrm{H}), 7.46(\mathrm{~m}, 5 \mathrm{H}$, per-H), $7.13\left(\mathrm{~m}, 2 \mathrm{H}\right.$, py-H), $4.08\left(\mathrm{~s}, 2 \mathrm{H}\right.$, per- $\left.\mathrm{CH}_{2}\right), 3.90$ (s, 4H, py-CH $\mathrm{CH}_{2}$. mp. 184-185 ${ }^{\circ} \mathrm{C}$. Elemental analysis (\%) calcd. for $\mathrm{C}_{33} \mathrm{H}_{25} \mathrm{~N}_{3}, \mathrm{C} 85.50 \mathrm{H} 5.44 \mathrm{~N} 9.06$; found, 
C 85.74 H 5.38 N 8.97.

\subsection{Syntheses of $\mathrm{Cu}(\mathrm{II})$ complexes}

\subsection{1. [Cu(perbpa) $\left.\mathrm{Cl}_{2}\right] \cdot 0.5 \mathrm{H}_{2} \mathrm{O}\left(2 \cdot 0.5 \mathrm{H}_{2} \mathrm{O}\right)$.}

To a methanol solution $(10 \mathrm{~mL})$ of $\mathrm{CuCl}_{2} \cdot 2 \mathrm{H}_{2} \mathrm{O}(0.094 \mathrm{~g}, 0.55 \mathrm{mmol})$ was added $1(0.24 \mathrm{~g}, 0.52 \mathrm{mmol})$ in dichloromethane $(10 \mathrm{~mL})$. The reaction mixture was filtrated and the filtrate was slowly evaporated to yield green platelets $(0.24 \mathrm{~g}, 78 \%)$. mp. $219{ }^{\circ} \mathrm{C}$ dec. Elemental analysis (\%) calcd. for $\mathrm{C}_{33} \mathrm{H}_{26} \mathrm{~N}_{3} \mathrm{Cl}_{2} \mathrm{CuO}_{0.5}, \mathrm{C} 65.29 \mathrm{H} 4.32$ N 6.92 Cl 11.68; found, C 65.28 H 4.51 N 6.90 Cl 11.58.

\subsection{2. $\left[\mathrm{Cu}_{2}(\mu-\mathrm{Cl})_{2}(\text { perbpa })_{2}\right] I_{5.6} \quad\left(3 \cdot I_{5.6}\right)$}

A methanol solution $(10 \mathrm{~mL})$ of $\mathrm{CuCl}_{2} \cdot 2 \mathrm{H}_{2} \mathrm{O}(0.016 \mathrm{~g}, 0.094 \mathrm{mmol})$ was mixed with a dichloromethane solution $(10 \mathrm{~mL})$ of $1(0.049 \mathrm{~g}, 0.11 \mathrm{mmol})$. Iodine $(0.050 \mathrm{~g})$ was added to the green reaction mixture and heated. After iodine was completely dissolved, the hot dark red solution was filtrated and the filtrate was left to stand for 3 days at room temperature to give deep red prisms (0.046 g, 47\%). mp. $202{ }^{\circ} \mathrm{C} \mathrm{dec}$. Elemental analysis (\%) calcd. for $\mathrm{C}_{66} \mathrm{H}_{50} \mathrm{~N}_{6} \mathrm{Cl}_{2} \mathrm{Cu}_{2} \mathrm{I}_{5.6}, \mathrm{C} 43.18 \mathrm{H} 2.75 \mathrm{~N} 4.58$; found, $\mathrm{C}$ $43.13 \mathrm{H} 2.52 \mathrm{~N} 4.34$. Owing to the volatile nature of iodine, the composition estimated from elemental analysis was different from that determined by X-ray diffraction analysis (vide infra).

\subsection{Crystal structure determinations}

The X-ray experiment for $\mathbf{1}$ was carried out for the well-shaped single crystal on a MAC Science DIP-2020K imaging plate diffractometer with graphite monochromated Mo K $\alpha$ radiation $(\lambda=0.71073 \AA)$ at $293 \mathrm{~K}$. The structure was solved by direct method. The refinement of structure was performed by full matrix least square method on $F^{2}$. The parameters were refined adopting anisotropic temperature factors for non-hydrogen atoms. The positions of hydrogen atoms were determined by calculation assuming $\mathrm{sp}^{2}$ or $\mathrm{sp}^{3}$ conformation and $\mathrm{C}-\mathrm{H}$ bond length of $0.95 \AA$. The parameters were refined adopting isotropic temperature factors for hydrogen atoms.

The X-ray experiments for $\mathbf{2}$ and $\mathbf{3}$ were carried out for the well-shaped single crystals on a Rigaku RAXIS imaging plate area detector with graphite monochromated 
Mo K $\alpha$ radiation $(\lambda=0.71073 \AA)$ at $130 \mathrm{~K}$. In order to determine the cell constants and orientation matrix, three oscillation photographs were taken for each frame with the oscillation angle of $3^{\circ}$ and the exposure time of $3 \mathrm{~min}$. Reflection data were corrected for both Lorentz and polarization effects. The structures were solved by the heavy-atom method and refined anisotropically for non-hydrogen atoms by full-matrix least-squares calculations. Atomic scattering factors and anomalous dispersion terms were taken from the literature [12]. Hydrogen atoms except those of the water molecules were located at the calculated positions and were assigned a fixed displacement and constrained to ideal geometry with $\mathrm{N}-\mathrm{H}=0.90 \AA$ and $\mathrm{C}-\mathrm{H}=0.95 \AA$. The thermal parameters of calculated hydrogen atoms were related to those of their parent atoms by $U(\mathrm{H})=1.2 U_{\mathrm{eq}}(\mathrm{C}, \mathrm{N})$. All the calculations were performed by using the Rigaku CrystalStructure ver. 3.5.1 program package. Summaries of the fundamental crystal data and experimental parameters for structure determination are given in Table 1.

\section{Results and discussion}

\subsection{Preparation of perylene-linked ligand and its copper(II) complexes}

The $\mathrm{Cu}(\mathrm{II})$ complex of $\left[\mathrm{Cu}(\mathrm{perbpa}) \mathrm{Cl}_{2}\right]$ (2) was synthesized by a reaction of ligand 1 with $\mathrm{CuCl}_{2} \cdot 2 \mathrm{H}_{2} \mathrm{O}$ at room temperature. The single crystals for X-ray analysis contain methanol $(\mathrm{MeOH})$ for crystallization, and so the composition of the $\mathrm{Cu}(\mathrm{II})$ complex estimated from X-ray analysis is $\mathbf{2} \cdot \mathbf{M e O H}$. The methanol easily escapes from crystals under ambient pressure. After removal of methanol by drying under reduced pressure of 0.1 Torr at room temperature for $2 \mathrm{~h}$, water was incorporated into the sample; and so the composition of the complex determined by an elemental analysis was therefore $2 \cdot 0.5 \mathrm{H}_{2} \mathrm{O}$. In order to obtain conducting material, chemical oxidation by iodine was carried out for the mixture of ligand 1 and $\mathrm{CuCl}_{2} \cdot 2 \mathrm{H}_{2} \mathrm{O}$. Dark red prisms of 3. $\left(\mathrm{I}_{3}\right)_{2}$ were obtained by the reaction with $\mathrm{I}_{2}$ in the $\mathrm{MeOH} / \mathrm{CH}_{2} \mathrm{Cl}_{2}$. $\mathrm{I}_{3}{ }^{-}$anion in $\mathbf{3}$ was partially sublimed to form $\mathrm{I}^{-}$anion even at ambient conditions. Elemental analysis reproducibly determined the composition to be $\left.\left[\mathrm{Cu}_{2} \mathrm{Cl}_{2} \text { (perbpa }\right)_{2}\right] \mathrm{I}_{5.6}$, which is assigned to $\left[\mathrm{Cu}^{2+}{ }_{2} \mathrm{Cl}_{2}^{-}\left(\text {perbpa }^{0}\right)_{2}\right]\left(\mathrm{I}_{3}\right)^{-}{ }_{1.8}(\mathrm{I})^{-}{ }_{0.2}$ since the optical and magnetic measurements confirmed that the the charges on the $\mathrm{Cu}$, perbpa, and $\mathrm{Cl}^{-}$species remained the same before and after the sublimation of $\mathrm{I}_{2}$. All of the synthetic schemes are summarized in Scheme 2. 


\subsection{Crystal structures}

$\mathbf{1}$ crystallizes in the orthorhombic system $(P b n b)$. The molecular structure of $\mathbf{1}$ is shown in the Supplementary material. Fig. 1a shows the $b$-axis projection for the packing structure of $\mathbf{1}$. Bond lengths of the perylene group are similar to those of the neutral form [13]. This results suggests that perylene moiety in $\mathbf{1}$ also is the neutral form. The interesting point is the formation of a two-dimensional segregated layer of the perylene groups in the $a b$-plane. This layer is composed of orthogonally aligned dimerized perylene groups (Fig. 1b). Such a packing structure is similar to that observed for neutral perylene crystal ( $\alpha$-form) [13]. The interplanar distance within a dimer is $3.45 \AA$, which is as long as that of the neutral perylene (3.45 $\AA$ ) [13]. These facts indicate that the $\pi-\pi$ interactions within the perylene layers predominate for the arrangement of perbpa molecules in the crystal and that ligand $\mathbf{1}$ has high potential to form a carrier path required for electric conductors. The two-dimensional perylene layers, with a the width of ca. $9 \AA$ for each, are separated by a thick layer (ca. $9 \AA$ ) composed of bpa groups along the $c$-axis (Fig. 1a).

$2 \cdot \mathrm{MeOH}$ crystallizes in the monoclinic system $\left(P 2_{1} / n\right)$. The molecular structure is shown in Fig. 2a. Selected bond distances and angles are summarized in Table 2. The X-ray crystal structure revealed that $\mathbf{2} \cdot \mathrm{MeOH}$ is a mononuclear penta-coordinate structure that incrudes two chloride ions, two pyridine nitrogens, and an amine nitrogen with $\mathrm{Cu}-\mathrm{N}$ bond lengths of $\mathrm{Cu}-\mathrm{N}(1) 2.007$ (4) $\AA, \mathrm{Cu}-\mathrm{N}(2) 2.046$ (4) $\AA$, and $\mathrm{Cu}-\mathrm{N}(3)$

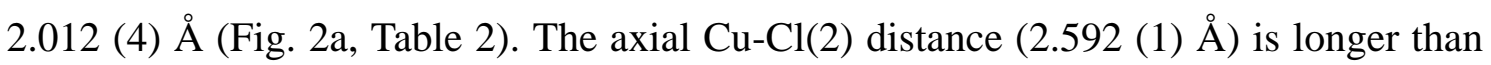
the other $\mathrm{Cu}-\mathrm{Cl}(1)$ distance $(2.247$ (1) $\AA$ ), this difference originated from the Jahn-Teller distortion typical for a $\mathrm{Cu}(\mathrm{II})$ complex of $\mathrm{d}^{9}$ electronic configuration. The coordination geometry in $\mathbf{2} \cdot \mathrm{MeOH}$ can therefore be described as a distorted square pyramid. The bond lengths of the perylene group are similar to those of non-functionized perylene [13]. An interesting point in the molecular structure for $2 \cdot \mathrm{MeOH}$ is that the perylene moiety faces to one of the pyridine moiety, which coordinates the $\mathrm{Cu}$ (II) centre (Fig. 2a). This suggests a $\pi-\pi$ stacking between the pyridine and perylene moieties. The distance between the pyridine moiety and the perylene moiety was estimated to be ca $3.67 \AA$, although these moieties were not parallel. These facts suggest that a weak $\pi-\pi$ interaction exists between pyridine and perylene moieties.

In the packing structure, a couple of perylene moieties of $\mathbf{2}$ form a dimer (Fig. 
$2 b)$ with the aid of the $\pi-\pi$ interaction between the perylene groups with a interplanar distance of $3.42 \AA$, which is a slightly shorter than the interplanar distance for nonfunctionalized perylene. Therefore, one perylene dimer is sandwiched by two pyridine rings to form a unit of pyridine-perylene-pyridine-perilene, encircled in Fig. 2b, and the units are arranged along the $b$-axis. However the conduction path for $\pi$-electron is deteriorated, by the inclusion of $\mathrm{MeOH}$ as depicted in Fig. $2 \mathrm{~b}$.

3. $\left(\mathrm{I}_{3}\right)_{2}$ crystallizes in the triclinic $(P 1)$ system. This complex consists of a binuclear $\left[(\text { perbpa }) \mathrm{Cu}(\mu-\mathrm{Cl})_{2} \mathrm{Cu} \text { (perbpa) }\right]^{2+}$ ion and two $\mathrm{I}_{3}^{-}$as counteranions. Bond lengths and angles of the coordination sphere are summarized in Table 2. Figure 3a depicts the molecular structure of 3 . The bridging $\mathrm{Cu}_{2} \mathrm{Cl}_{2}$ unit is constrained to be planar, and the crystallographic inversion centre is allocated at the middle of the molecule. Each $\mathrm{Cu}$ ion in $\mathbf{3} \cdot\left(\mathrm{I}_{3}\right)_{2}$ is coordinated to three nitrogen atoms in the perbpa ligand and two chloride ions in a slightly distorted square-pyramidal geometry. Similar to the structure of $2 \cdot \mathrm{MeOH}$, one chloride ion is in the basal plane $(\mathrm{Cu} 1-\mathrm{Cl} 1=2.257(1) \AA)$ and another chloride ion is located on the apical position $\left(\mathrm{Cu} 1-\mathrm{Cl1}{ }^{\prime}=2.643(1) \AA\right.$ ). Two square pyramids share a base-to-apex edge so that the $\mathrm{Cl}$ atom situated at the vertex of one base becomes the apical vertex of the other square pyramid, and the opposite happens for the other Cl-bridging ligand. Such a coordination structure was categorized as 'parallel-type' in literature [14]. The bond angle of Cu1-Cl1-Cu1' is 84.29(4) ${ }^{\circ}$. Bond lengths of the perylene group in $\mathbf{3} \cdot\left(\mathrm{I}_{3}\right)_{2}$ are similar to those of the neutral perylene molecule and those in $\mathbf{2} \cdot \mathrm{MeOH}$. In the molecular structure, in contrast to that of $\mathbf{2} \cdot \mathrm{MeOH}$, the perylene group faces opposite side of the coordination centre and not stacks with pyridine groups coordinating to $\mathrm{Cu}$ (II) (Fig. 3a). In the packing structure, perylene groups form dimers, which are isolated with an intradimer perylene plane distance of $3.47 \AA$, slightly longer than that for nonfunctionalized perylene (Fig. 3b). This indicates that the conduction path neither exists in $\mathbf{3} \cdot\left(\mathrm{I}_{3}\right)_{2}$.

\subsection{Optical spectra}

The UV-vis absorption spectrum of $2 \cdot 0.5 \mathrm{H}_{2} \mathrm{O}$ in DMF solution showed four peaks $(375,398,422$, and $448 \mathrm{~nm}$ ) (Fig. 4). These peaks are assignable to a perylene $\pi-\pi^{*}$ transition band with a vibronic structure $(368,387,409$, and $435 \mathrm{~nm}$ in cyclohexane [15]). The spectrum of $\mathbf{3} \cdot \mathrm{I}_{5.6}$ was a superposition of the absorption of $\mathbf{2}$ and 
that of $n-\mathrm{Bu}_{4} \mathrm{NI}_{3}(365 \mathrm{~nm})$. The absorption spectrum of the solid state, using the $\mathrm{KBr}$ method, corresponded to the absorption spectrum in solution (Fig. 5). A small absorption band at $12-13 \times 10^{3} \mathrm{~cm}^{-1}$, seen for $3 \cdot \mathrm{I}_{5.6}$ in the $\mathrm{KBr}$ method, is assignable to the $d-d$ band of the $\mathrm{Cu}(\mathrm{II})$ centre. These results suggest that the perylene group in $\mathbf{3}$ is not cationic but in the neutral electronic state.

\subsection{Magnetic properties of copper complexes.}

Temperature dependences of the $\chi T$ products for $2 \cdot 0.5 \mathrm{H}_{2} \mathrm{O}$ and $3 \cdot \mathrm{I}_{5.6}$ are shown in Fig. 6. $2 \cdot 0.5 \mathrm{H}_{2} \mathrm{O}$ shows Curie-Weiss (eq. 1) behaviour typical for a square-pyramidal mononuclear $\mathrm{Cu}(\mathrm{II})$ complex $(S=1 / 2, g=2.13, \Theta=-0.265 \mathrm{~K})$ :

$$
\chi=\frac{N g^{2} \mu_{B}^{2} S(S+1)}{3 k(T-\Theta)}
$$

On the other hand, the $\chi T$ product for $3 \cdot I_{5.6}$ behaves differently from that of $2 \cdot 0.5 \mathrm{H}_{2} \mathrm{O}$. The $\chi T$ product at $300 \mathrm{~K}$ is $0.901 \mathrm{emu} \mathrm{K} \mathrm{mol}^{-1}$ for $3 \cdot \mathrm{I}_{5.6}$, which is a reasonable value for noninteracting two $S=1 / 2$ spins $(\chi T=0.902$ for $g=2.06)$. At low temperatures, the $\chi T$ product slightly increases due to the intramolecular ferromagnetic coupling of chloride bridged $\mathrm{Cu}(\mathrm{II})$ centres. The simple Bleany-Bowers equation [16] is unacceptable for these compounds because singlet-triplet energy gaps estimated based on the basis of such an equation are comparable to Zeeman splitting $\left(\left|E_{\mathrm{S}-\mathrm{T}}\right|=2|J| \sim\right.$ $\left.g \mu_{B} H\right)$. Friedberg's magnetization expression [17] is applied for fittings of the data. Friedberg's expression is given by eqs. 2 and 3,

$$
\begin{aligned}
& M=\frac{2 N g \mu_{\mathrm{B}} \sinh \left(g \mu_{\mathrm{B}} H / k T\right)}{\exp (-2 J / k T)+2 \cosh \left(g \mu_{\mathrm{B}} H / k T\right)+1} \\
& \chi-N \alpha=M / H
\end{aligned}
$$

for isotropic exchange Hamiltonian of eq. 4

$$
\hat{H}=-2 J \hat{S}_{1} \cdot \hat{S}_{2}
$$

, where $N \alpha$ is a temperature-independent paramagnetism. The susceptibility data are fitted to the values of $g=2.12, J=+1.17 \mathrm{~cm}^{-1}$, and $N \alpha=1.55 \times 10^{-4} \mathrm{emu} \mathrm{mol}^{-1}$ for $3 \cdot \mathrm{I}_{5.6}$. The excellent fit and small $J$ value together with such 'parallel-type' geometry indicate 
that the magnetic interaction between the copper centres takes place mainly through a $\pi^{*}$ type of interaction between $\mathrm{Cu} \mathrm{d}_{\mathrm{x}^{2}-\mathrm{y}^{2}}$ and the apical $\mathrm{p}_{\mathrm{Cl}}$ orbitals, which is in good agreement with previous theoretical and experimental works [14].

An X-band EPR spectrum of a polycrystalline sample of $\mathbf{3} \cdot \mathrm{I}_{5.6}$ at $4 \mathrm{~K}$ provided detailed information about the spin state. $3 \cdot I_{5.6}$ showed $g$-tensor anisotropy with $g_{/ /}=$ 2.122 and $g \perp=2.054$. Moreover, a half-field resonance of $g=4.235(\Delta M \mathrm{~s}= \pm 2)$ was observed in the spectrum. The half-field resonance decreased as temperature increased even though the signal remained at $300 \mathrm{~K}$. This result clearly indicates the triplet $(S=1)$ ground state of the $\mathrm{Cu}(\mathrm{II})$ binuclear system. The EPR spectrum of a DMF frozen solution of $\mathbf{3} \cdot \mathrm{I}_{5.6}$ at $77 \mathrm{~K}$ is typical for the spectrum of axially distorted $\mathrm{Cu}$ (II) complexes $\left(g_{/ /}=2.224, g_{\perp}=2.041\right.$, and $\left.a_{/ /}=17.6 \mathrm{mT}\right)$. In a previous work of Fe(II) TTFbpa complex, sharp EPR signals with hyperfine splitting at around $g=2.00$ originating from the radical state of the TTF group were only detected in an acetonitrile $(\mathrm{MeCN})$ solution but not in a powder sample because of the strong anti-ferromagnetic coupling between the TTF cation radical groups in a solid state [6]. In the case of $\mathbf{3}$, such a sharp EPR signal around $g=2.00$ was not detected in either a polycrystalline state or in a DMF frozen solution. These magnetic properties for $3 \cdot \mathrm{I}_{5.6}$ are consistent with the crystal structure and absorption spectrum.

\subsection{Electrochemical studies}

From the studies described above, $\mathbf{3} \cdot \mathrm{I}_{5.6}$ has a ferromagnetically coupled ground state with two electron spins on each $\mathrm{Cu}$ (II) binuclear ion, while the perylene moiety is not in the cation radical state. These results indicate that the chemical oxidation by $\mathrm{I}_{2}$ did not yield ligand-centred oxidized species but yielded species with neutral ligands. The formation of $\mathbf{3} \cdot \mathrm{I}_{5.6}$ proceeded through the formation of $\mathrm{I}_{3}{ }^{-}$anion, which was a reduced product of $I_{2}$, indicating the redox process is the key step toward compound $3 \cdot \mathrm{I}_{5.6}$.

To examine the formation processes, electrochemical properties of ligand $\mathbf{1}$ and the $\mathrm{Cu}$ (II) complex $\mathbf{2} \cdot 0.5 \mathrm{H}_{2} \mathrm{O}$ were investigated. A cyclic voltammogram of 1 showed irreversible oxidation peaks at $+0.86 \mathrm{~V}$ and $+0.98 \mathrm{~V}$ vs. $\mathrm{Ag} / \mathrm{AgCl}$ (Fig. 7). Since TTF-pendent ligand TTFbpa exhibited three anodic peaks at $+0.232,+0.564$, and $+0.856 \mathrm{~V}$ vs. $\mathrm{Ag} / \mathrm{AgCl}$ by $\mathrm{DPV}$ measurement and the former two peaks correspond to 
those of pristine TTF $(+0.248$ and $0.612 \mathrm{~V})$, the peak at $+0.856 \mathrm{~V}$ is assignable to that of the bpa moiety in TTFbpa [6]. Even though the measurement condition was different (solvent used in the measurement for TTFbpa was $\mathrm{MeCN}$ ), the oxidation peak at +0.86 $\mathrm{V}$ observed in $\mathbf{1}$ may be ascribed to that of the bpa moiety in perbpa. The oxidation peak at $+0.98 \mathrm{~V}$ corresponds to the perylene moiety of $\mathbf{1}$. A cyclic voltammogram of $2 \cdot 0.5 \mathrm{H}_{2} \mathrm{O}$, on the other hand, showed an irreversible oxidation peak at $+0.96 \mathrm{~V}$ (Fig. 7). The peak at $+0.86 \mathrm{~V}$ in the voltammogram of $\mathbf{1}$ is absent in the voltammogram of $2 \cdot 0.5 \mathrm{H}_{2} \mathrm{O}$ because the coordination of the amino group in the bpa moiety to the $\mathrm{Cu}$ (II) ion lowered the electron density on the anino- $\mathrm{N}$ atom in HOMO, and hence the oxidation potential of the bpa group increased. Oxidation potentials of $1,2 \cdot 0.5 \mathrm{H}_{2} \mathrm{O}$, and perylene in DMF were precisely determined by DPV measurements (Table 3). Scheme 3 shows a plausible mechanism of formation of $3 \cdot\left(\mathrm{I}_{3}\right)_{2}$ based on electrochemical studies. The $\mathrm{Cu}(\mathrm{II})$ complex is labile in general, so in the solution of $2 \cdot 0.5 \mathrm{H}_{2} \mathrm{O}$, a small quantity of perbpa may be released, or $\mathrm{Cl}^{-}$may be released to generate dinuclear species of $\mathbf{3}$. When $\mathrm{I}_{2}$ is added to such a solution, although perbpa coordinating to the $\mathrm{Cu}(\mathrm{II})$ ion is inert to oxidation, bpa would be quickly oxidized in the released perbpa. This redox process generates unidentified decomposed species and an $\mathrm{I}_{3}{ }^{-}$ion which forms $\left[(\text { perbpa })^{0} \mathrm{Cu}^{\mathrm{II}}\left(\mu-\mathrm{Cl}_{2}\right) \mathrm{Cu}^{\mathrm{II}}(\text { perbpa })^{0}\right]\left(\mathrm{I}_{3}\right)_{2}$.

\section{Conclusion}

We prepared and characterized a new tridentate ligand, perbpa 1, containing three nitrogen atoms for coordination and one perylene group for the $\pi$-electron reservoir and studied electronic and structural properties of its $\mathrm{Cu}(\mathrm{II})$ complexes. The refined crystal structure indicated that ligand $\mathbf{1}$ has a high potential to form the conduction path required for the electric conductors. The crystal structure of the mononuclear $\mathrm{Cu}(\mathrm{II})$ complex $\mathbf{2} \cdot \mathrm{MeOH}$ revealed a distorted square-pyramidal coordination geometry around $\mathrm{Cu}(\mathrm{II})$. The reaction of $\mathrm{CuCl}_{2} \cdot 2 \mathrm{H}_{2} \mathrm{O}$ perbpa and iodine yielded an unprecedented dichloro-bridged binuclear $\mathrm{Cu}(\mathrm{II})$ complex $\mathbf{3} \cdot\left(\mathrm{I}_{3}\right)_{2}$ with a neutral perylene-pendent ligand. This binuclear $\mathrm{Cu}(\mathrm{II})$ complex exhibited weakly ferromagnetic coupling with two $\mathrm{S}=1 / 2 \mathrm{Cu}$ (II) centres. The formation of an $\mathrm{I}_{3}{ }^{-}$anion is due to the oxidation of the bpa group. 


\section{Supplementary material}

Crystallographic data (excluding structure factors) for $\mathbf{1}, \mathbf{2} \cdot \mathrm{MeOH}$, and $\mathbf{3} \cdot\left(\mathrm{I}_{3}\right)_{2}$ have been deposited with the Cambridge Crystallographic Data Centre (CCDC) as supplementary publication numbers CCDC-763642 for $\mathbf{1}, 763643$ for $\mathbf{2} \cdot \mathrm{MeOH}$, and 76344 for $3 \cdot\left(\mathrm{I}_{3}\right)_{2}$. Copies of the data can be obtained free of charge on application to CCDC, 12 Union Road, Cambridge CB2 1EZ, UK (fax: (+44)1223-336-003; e-mail: deposit@ccdc.cam.ac.uk). Supplementary data (elemental analysis simulation for 3, molecular structure of $\mathbf{1}$, bond lengths of perylene groups and distances between perylene planes for $\mathbf{1}, \mathbf{2} \cdot \mathrm{MeOH}$, and $\mathbf{3} \cdot\left(\mathrm{I}_{3}\right)_{2}$, EPR spectra of $\mathbf{3} \cdot \mathrm{I}_{5.6}$, and DPV voltammograms for $1,2 \cdot 0.5 \mathrm{H}_{2} \mathrm{O}$, and perylene can be found in the online.

\section{Acknowledgement}

This work was financially supported by 21 st century COE program of Kyoto University.

\section{References}

[1] (a) J. Kondo, Prog. Theor. Phys. 32 (1964) 372. (b) R. Ramirez, L. M. Falicov, Phys. Rev. B 3 (1971) 2425.

[2](a) M. A. Ruderman, C. Kittel, Phys. Rev. 96 (1954) 99. (b) T. Kasuya, Prog. Theor. Phys. 16 (1956) 45; (c) K. Yoshida, Phys. Rev. 106 (1957) 893.

[3] (a) G. Binasch, P. Grünberg, F. Saurenbach, W. Zinn, Phys. Rev. B 39 (1989) 4828.

(b) M. N. Baibich, J. M. Broto, A. Fert, F. Nguyen Van Dau, F. Petroff, P. Eitenne, G. Creuzet, A. Friedrich, J. Chazelas, Phys. Rev. Lett. 61 (1988) 2472.

[4] (a) E. Coronado, P. Day, Chem. Rev. 104 (2004) 5419. (b)T.Enoki, A. Miyazaki, Chem. Rev. 104 (2004)5449. (c) T. Inabe, Chem. Rev. 104 (2004) 5503.

[5] D. Lorcy, N. Bellec, M. Formigué, N. Avarvari, Coord. Chem. Rev. 253 (2009) 1398 and references herein.

[6] J. Hagiwara, G. Saito, in Multifunctional Conducting Molecular Materials, eds. G.Saito, F. Wudl, R. C. Haddon, K. Tanigaki, T. Enoki, H. E. Katz, M. Maesato, RSC Publishing, Cambridge, UK. (2007) pp. 169.

[7] H.Akamatu, H.Inokuchi, Y. Matsunaga, Nature 173 (1954) 168. 
[8] (a) V. Gama, M. Almeida, R. T. Henriques, I. C. Santos, Â. Domingos, S. Ravy, J. P. Pouget, J. Phys. Chem. 95 (1991) 4263. (b) V. Gama, R. T. Henriques, M. Almeida, L. Alcácer, ibid, 98 (1994) 997.

[9] U. Asseline, E. Cheng, Tetrahedron Lett. 42 (2001) 9005.

[10] D. D. Perrin, W. L. F. Armarego, Purification of Laboratory Chemicals $2^{\text {nd }}$ Ed., Pergamon Press, 1980.

[11] C. J. O’Connor, Prog. Inorg. Chem. 29 (1982) 203.

[12] (a) D. T. Cromer, J. T. Waber, International Tables for X-ray Crystallography, The Kynoch Press, Birmingham Vol. IV (1974). (b) J. A. Ibers, W. C. Hamilton, Acta Crystallogr. 17 (1964) 781. (c) D. C. Creagh, J. H. Hubbell, International Tables for Crystallography, Kluwer Academic Publishers, Boston, Vol. C (1992)

[13] A. Camerman, J. Trotter, Proc. R. Soc. Lond. A279 (1964) 129.

[14] M. Rodríguez, A. Liobet, M. Corbella, Polyhedron 19 (2000) 2483.

[15] H. Du, R. A. Fuh, J. Li, A. Corkan, J. S. Lindsey, Photochem. Photobiol. 68, (1998) 141

[16] B. Bleaney, K. D. Bowers, Proc. R. Soc. Lond. A214 (1952) 451.

[17] B. E. Meyers, L. Berger, S. A. Friedberg, J. Appl. Phys. 40 (1969) 1149. 


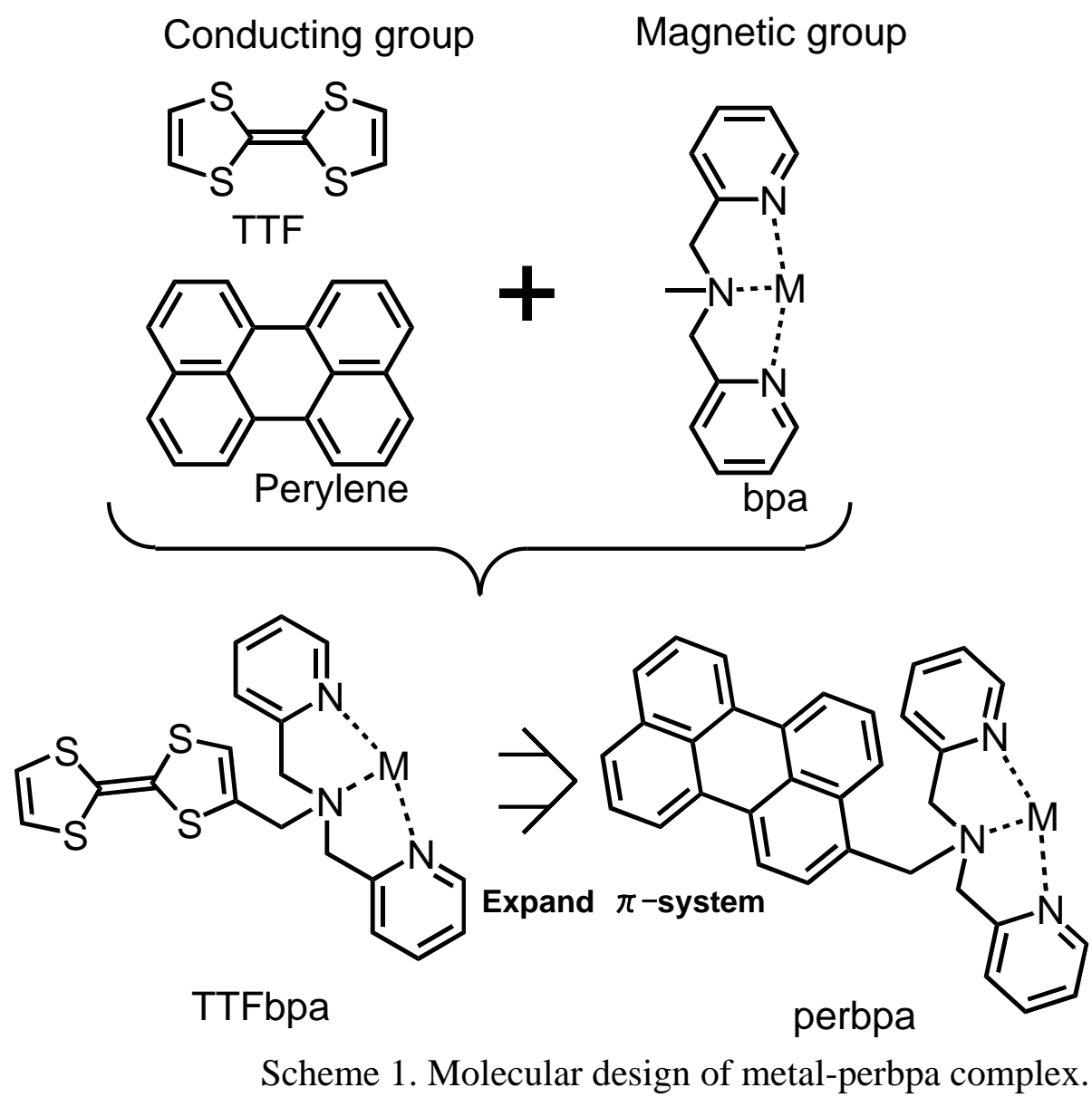



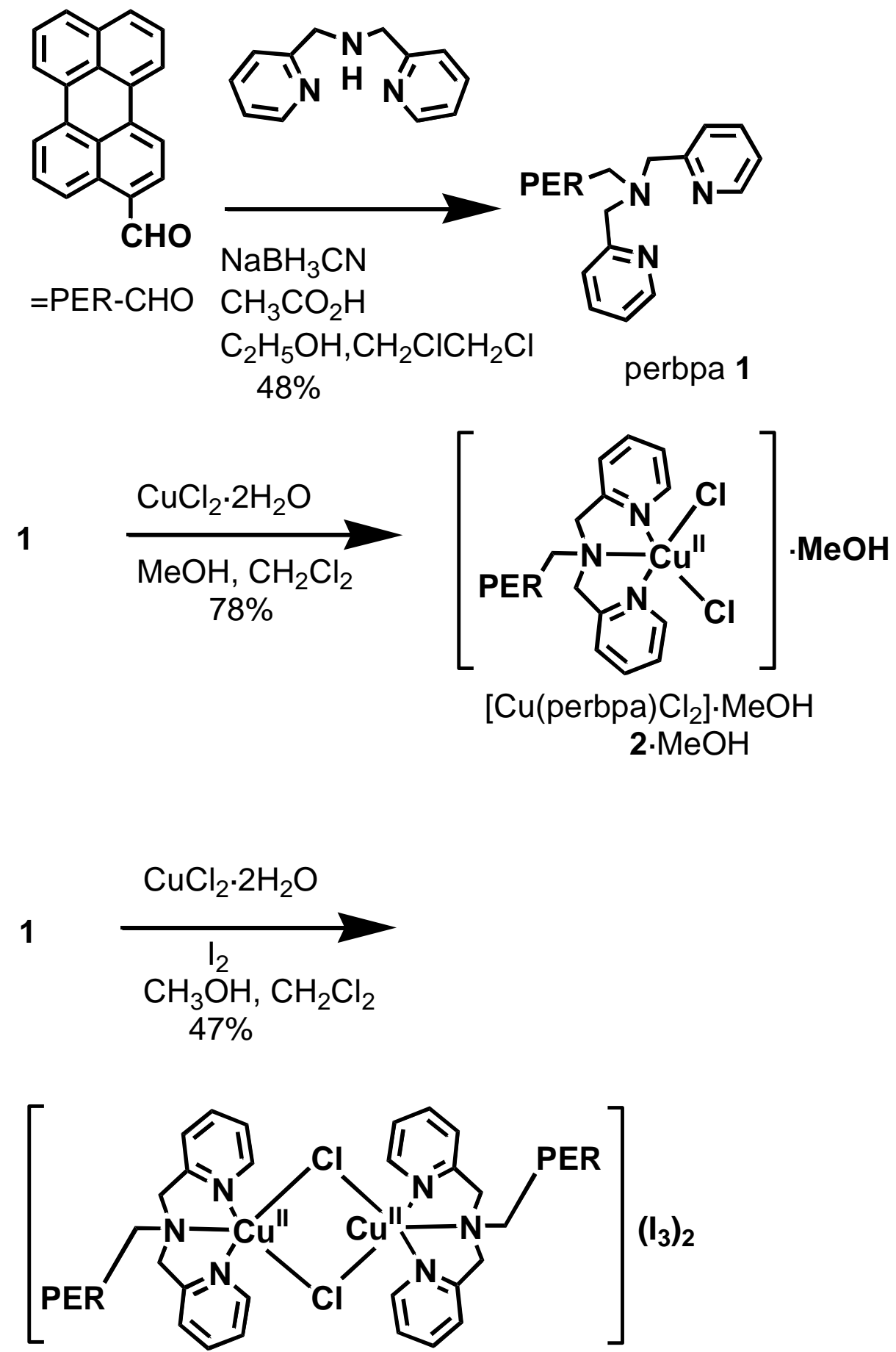

$\left[\mathrm{Cu}_{2}(\mu-\mathrm{Cl})_{2}(\text { perbpa })_{2}\right]\left(\mathrm{I}_{3}\right)_{2}$ $3 \cdot\left(I_{3}\right)_{2}$

Scheme 2. Synthetic routes for compounds 1, 2, and 3. 

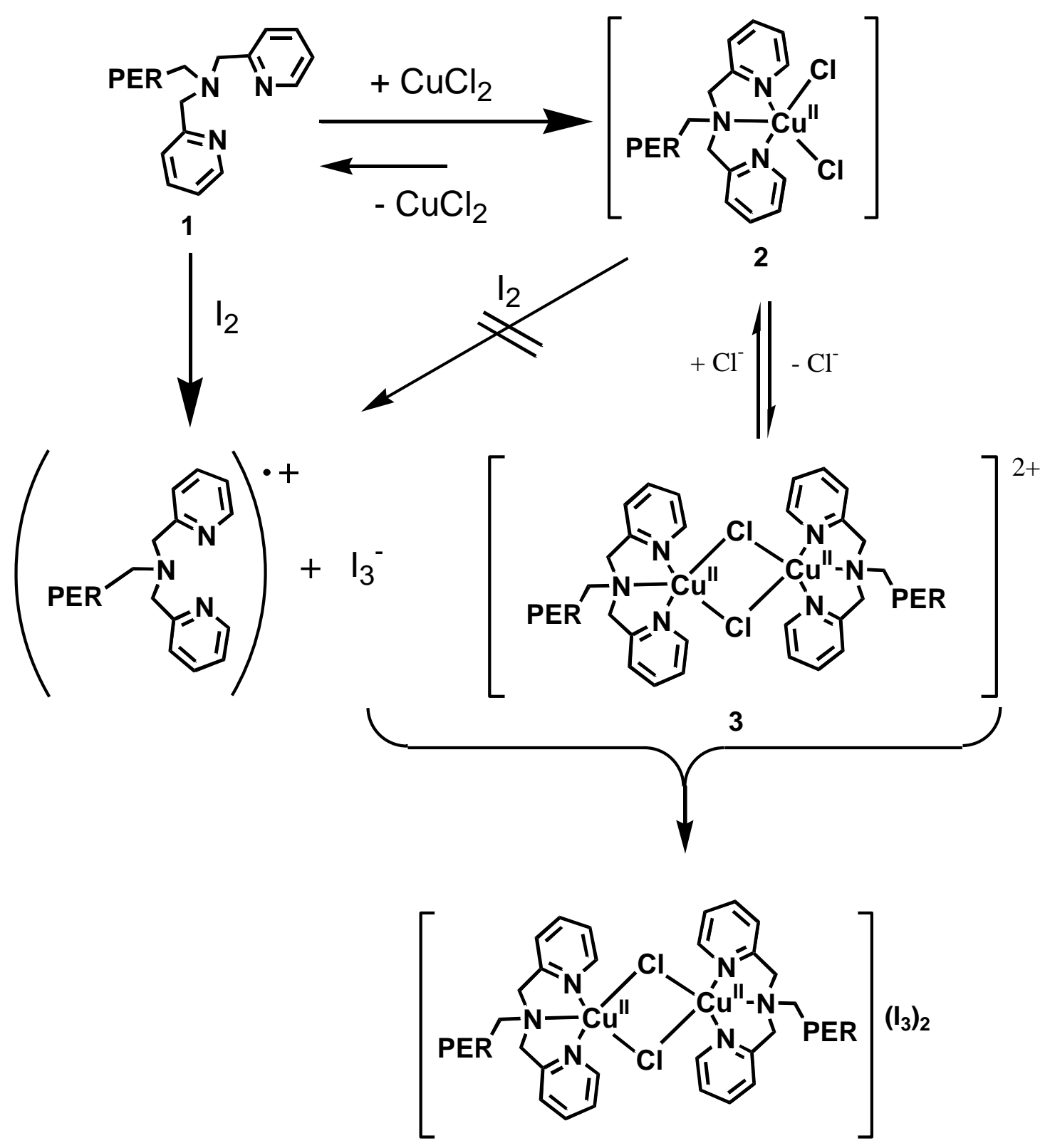

$$
3 \cdot\left(I_{3}\right)_{2}
$$

Scheme 3. Mechanism of formation of $\mathbf{3} \cdot\left(\mathrm{I}_{3}\right)_{2}$ proposed in this paper. 
(a)

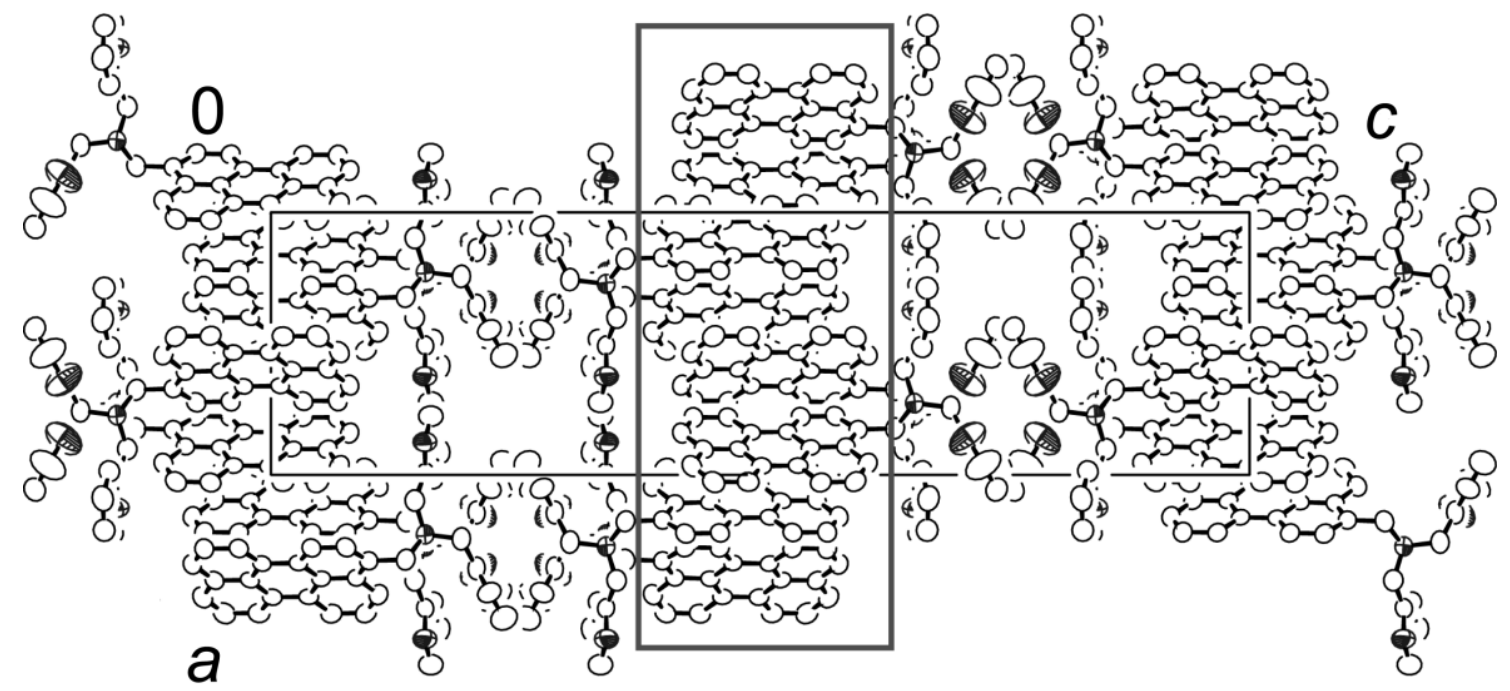

(b)

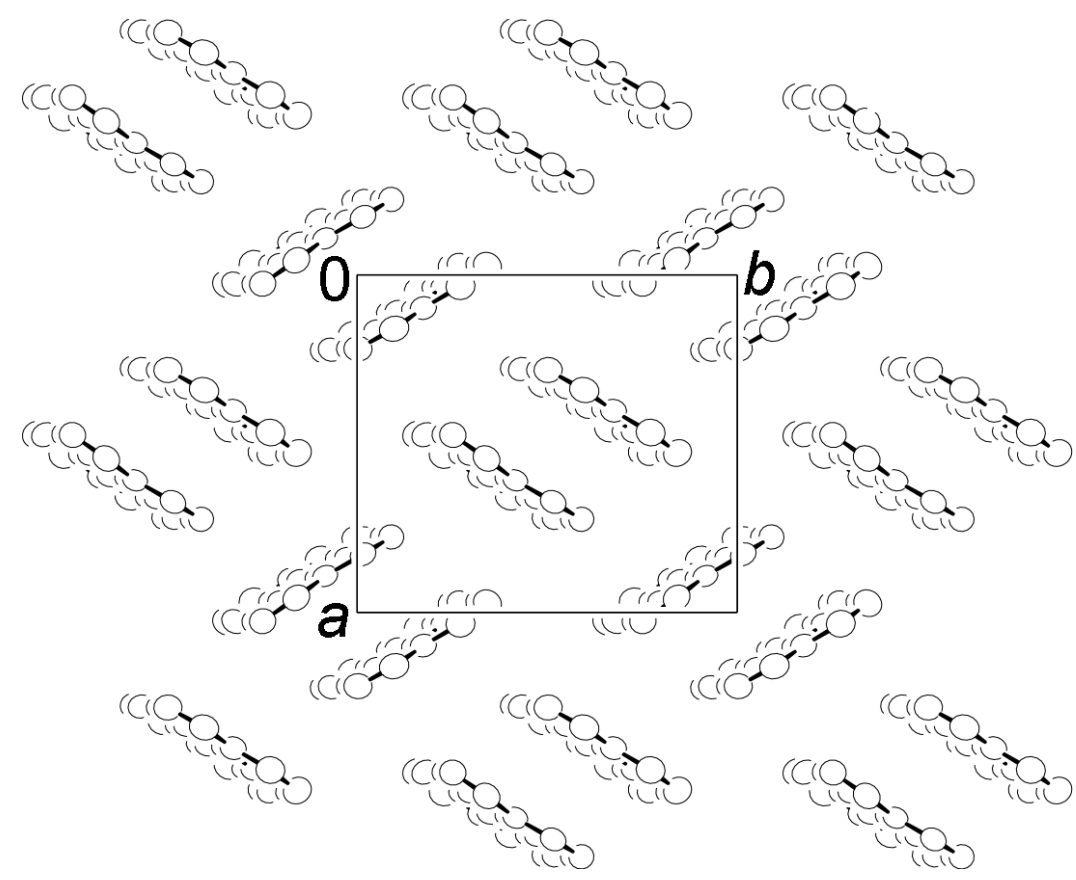

Figure 1. (a) Packing view (b-axis projection) of 1. A gray square indicates an aggregation of perylene groups. (b) Aggregation mode of perylene moieties of $\mathbf{1}$ ( $c$-axis projection). 
(a)

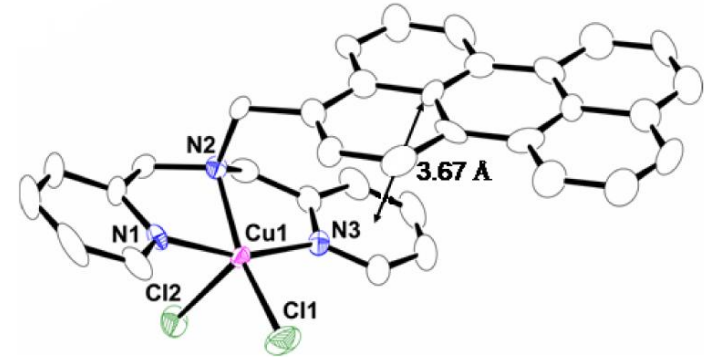

(b)

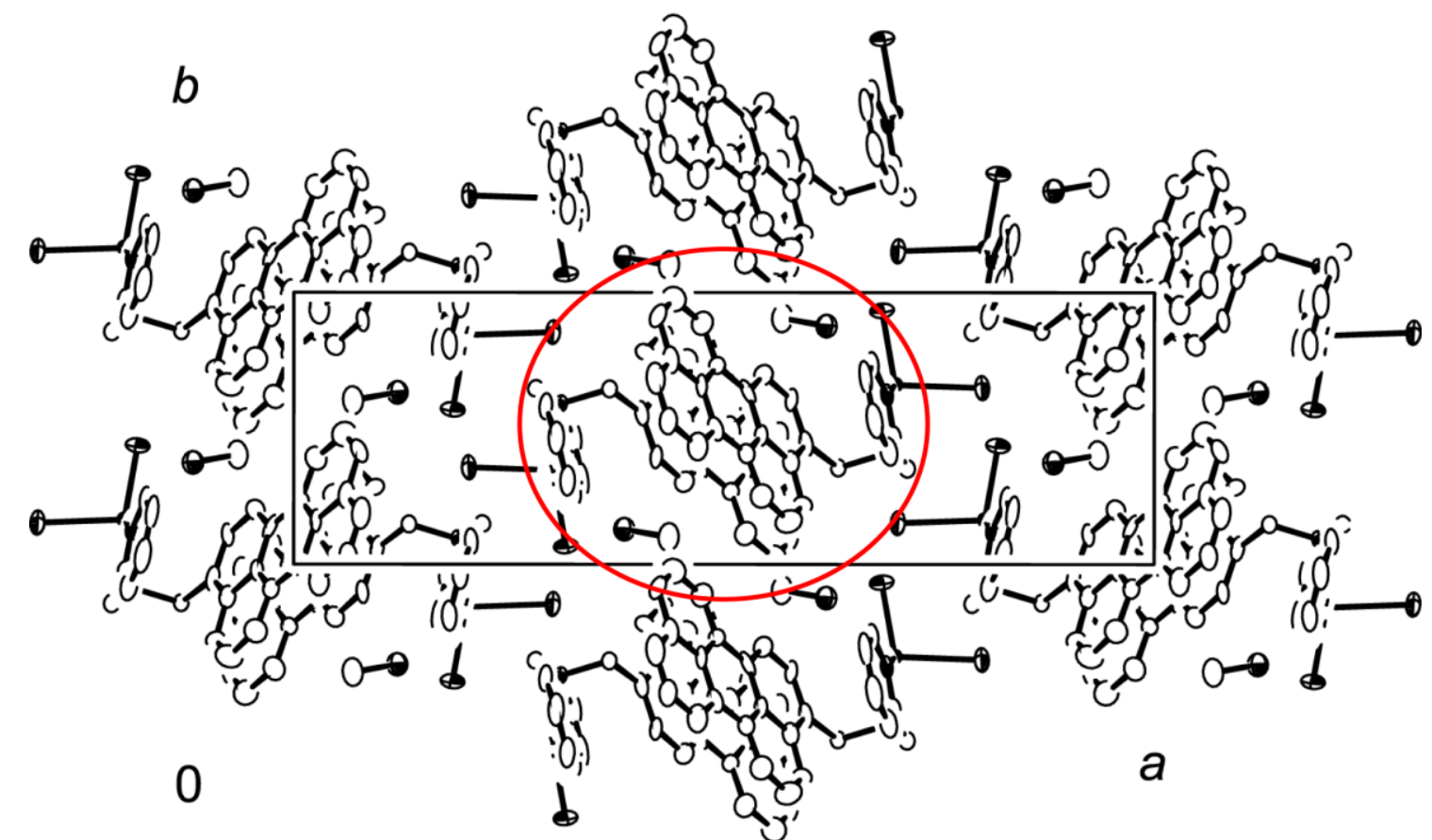


Figure 2. (a) Molecular structure of $\mathbf{2}$ in $\mathbf{2} \cdot \mathrm{MeOH}$ with thermal ellipsoids at $50 \%$ probability. (b) Packing view ( $c$-axis prejection) of. 2 $\mathrm{MeOH}$. A red ellipsoid represents an aggrregation of pyridine-perylene-perylene-pyridine moieties (see text). Hydrogen atoms are omitted for clarity. 


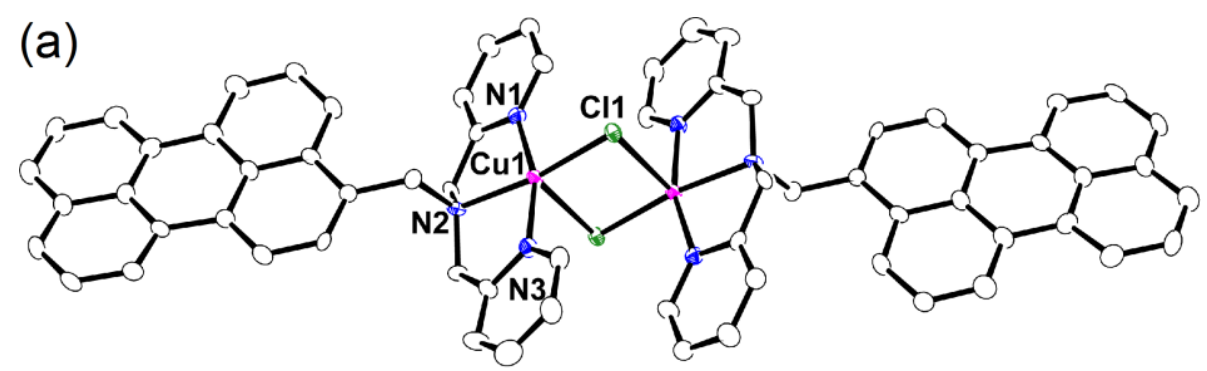

(b)

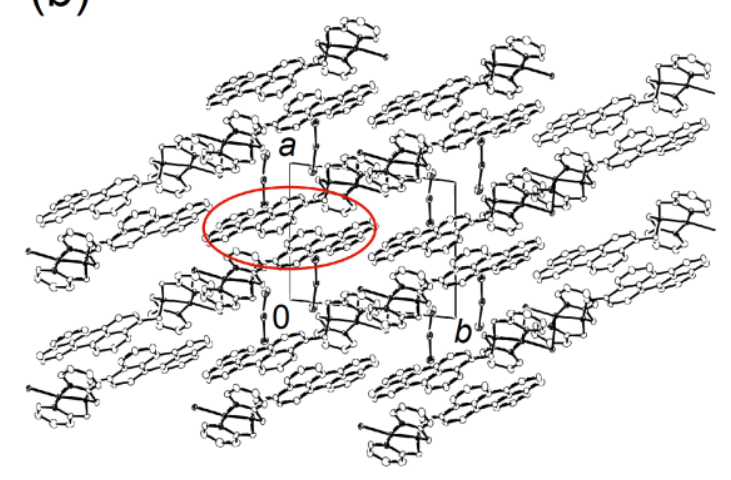

Figure 3. (a) Molecular structure of $\mathbf{3}$ in $\mathbf{3} \cdot\left(\mathrm{I}_{3}\right)_{2}$ with thermal ellipsoids at $50 \%$ probability. (b) Packing view ( $a$-axis projection) of $\mathbf{3} \cdot\left(\mathrm{I}_{3}\right)_{2}$. A red ellipsoid represents a dimer of perylene moieties. Hydrogen atoms are omitted for clarity. 


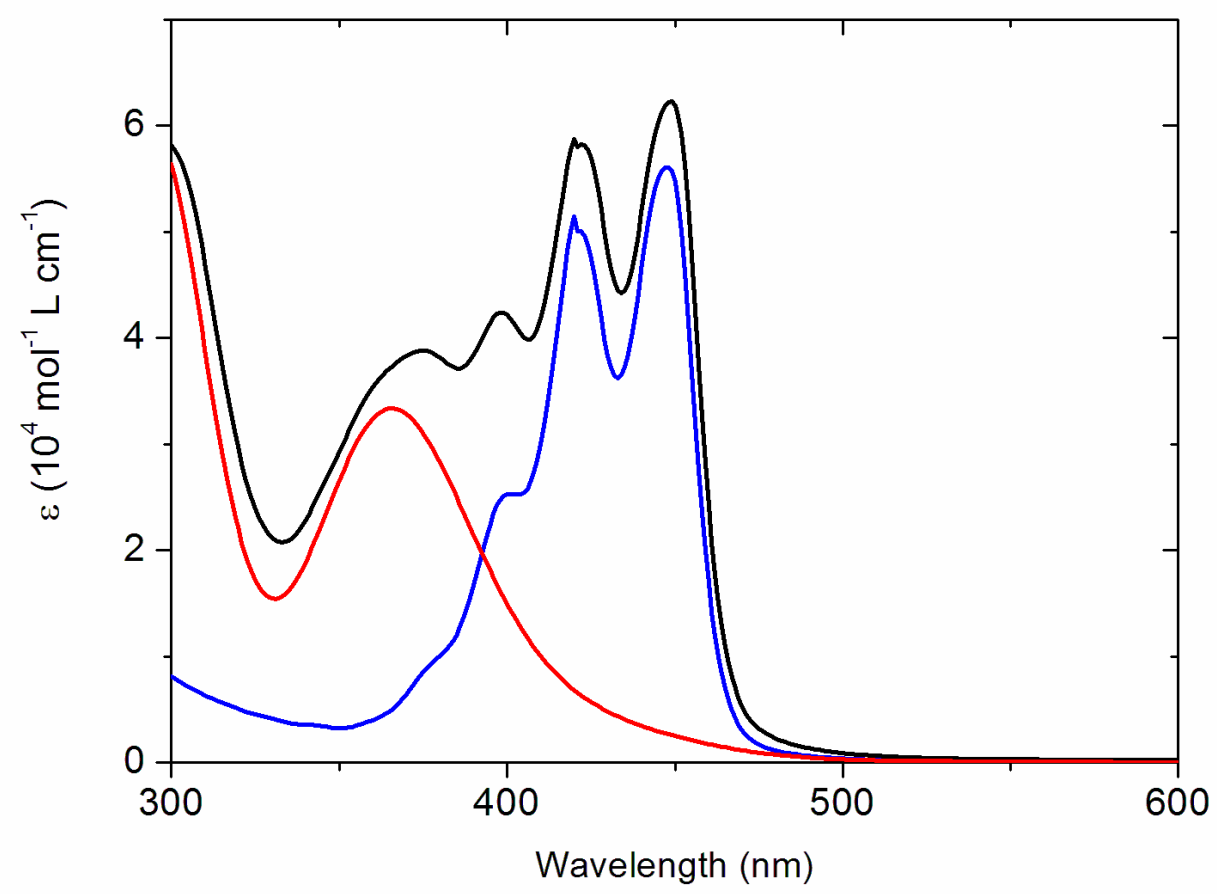

Figure 4. UV-vis absorption spectra for $2 \cdot 0.5 \mathrm{H}_{2} \mathrm{O}$ (blue), $3 \cdot \mathrm{I}_{5.6}$ (black), and $n$ - $\mathrm{Bu}_{4} \mathrm{NI}_{3}$ (red) in DMF solution. 


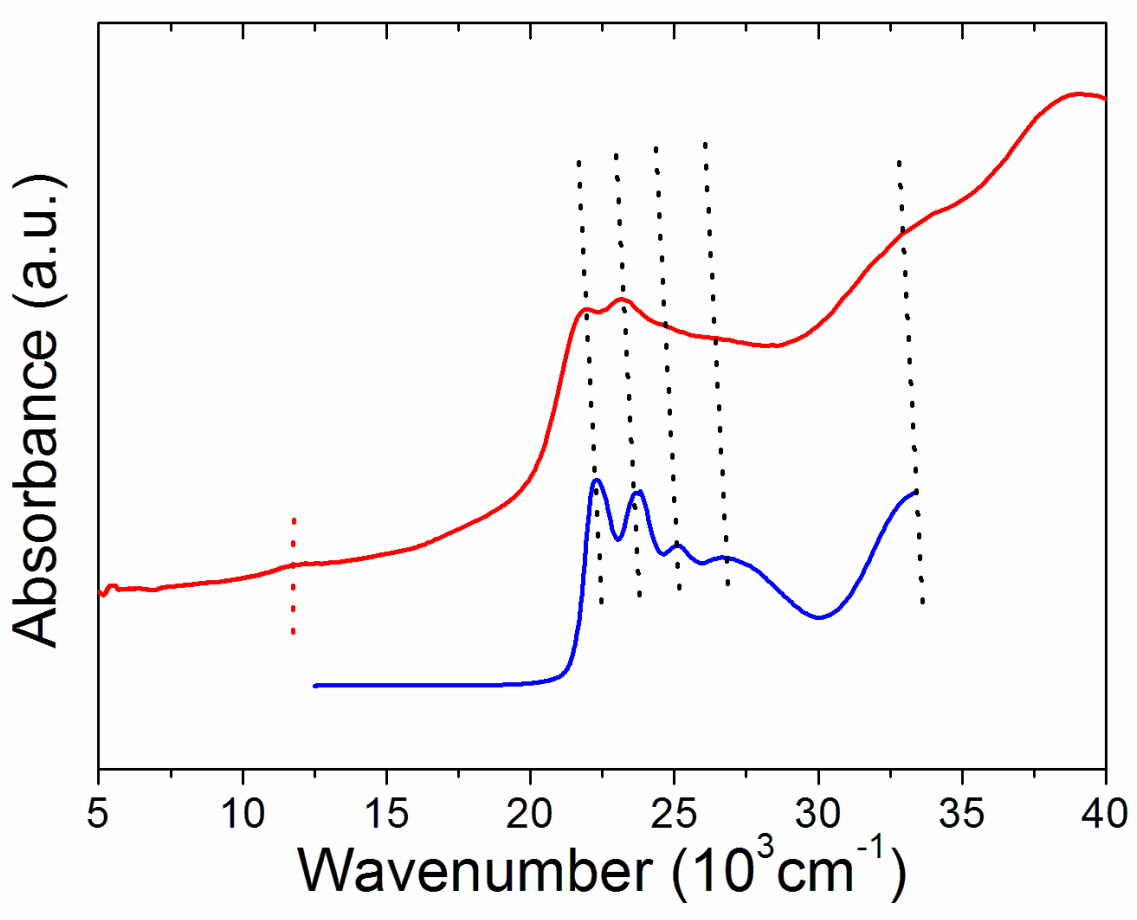

Figure 5. UV-vis absorption spectra for $3 \cdot \mathrm{I}_{5.6}$ in $\mathrm{DMF}$ solution (blue), and in $\mathrm{KBr}$ pellet(red). Black dotted lines represent absorption peaks of perbpa moieties (see text). A red dotted line indicates the $\mathrm{d}-\mathrm{d}$ transition of $\mathrm{Cu}(\mathrm{II})$. 


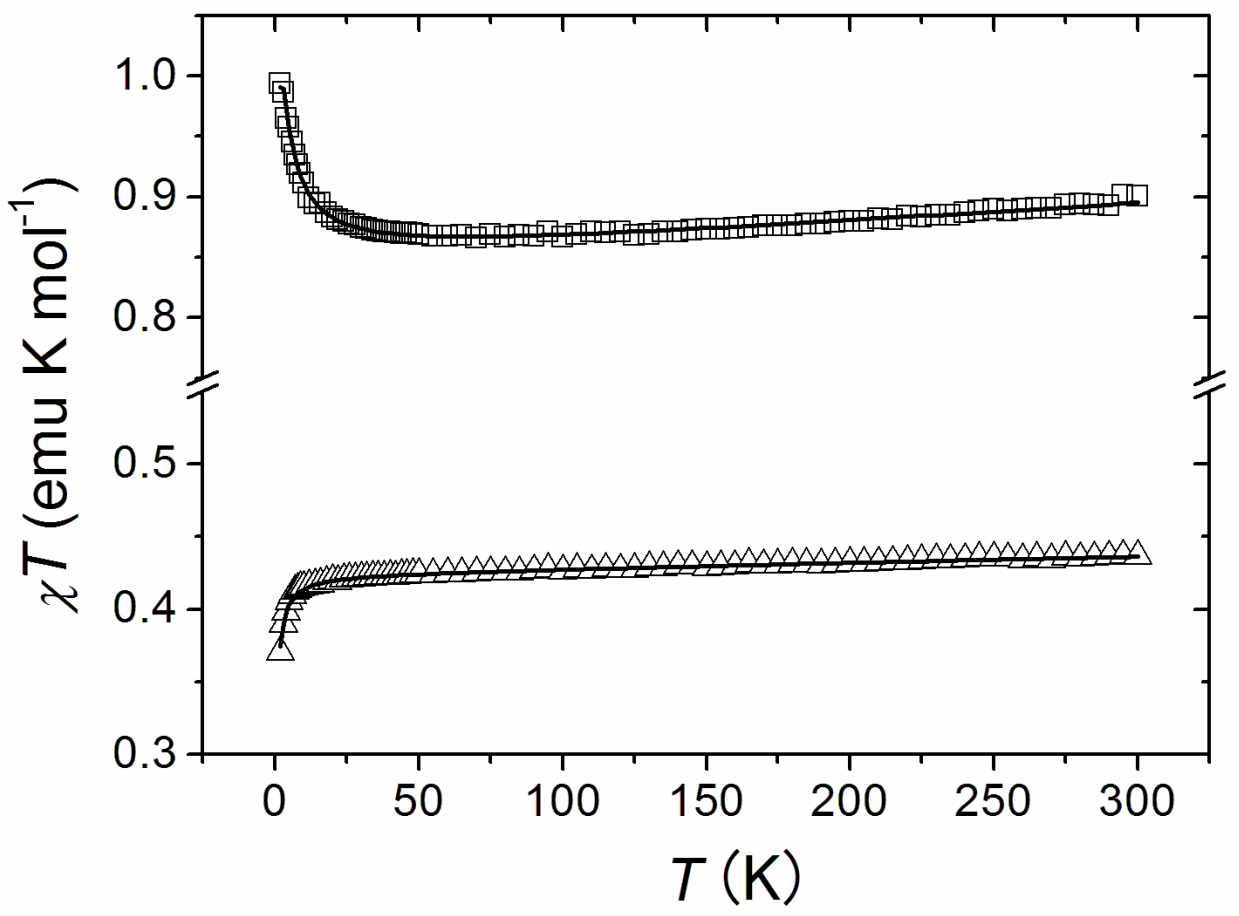

Figure 6. Temperature dependence of static susceptibilities for $2 \cdot 0.5 \mathrm{H}_{2} \mathrm{O}$ (triangle) and 3. $\mathrm{I}_{5.6}$ (square). Solid lines over the data are the results of the curve fitting calculations (see text). 


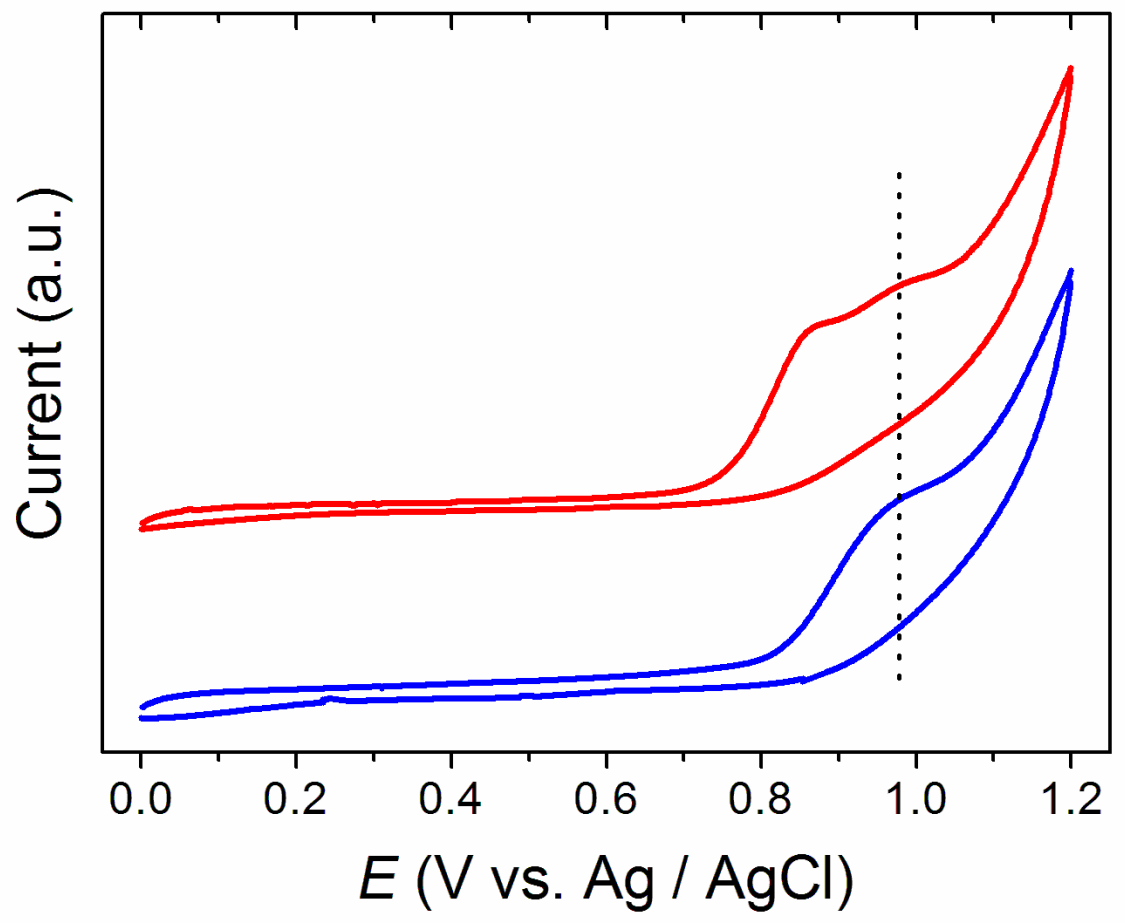

Figure 7. Cyclic voltammograms of $\mathbf{1}$ (red) and $2 \cdot 0.5 \mathrm{H}_{2} \mathrm{O}$ (blue) in DMF solution. A dotted line represents the oxidation potential of perylene moieties (see text). 
Table 1. Crystallographic data for perbpa and its copper complexes.

\begin{tabular}{|c|c|c|c|}
\hline Compound & $\begin{array}{c}\text { perbpa } \\
\mathbf{1}\end{array}$ & $\begin{array}{c}{\left[\mathrm{Cu}(\text { perbpa }) \mathrm{Cl}_{2}\right] \cdot \mathrm{MeOH}} \\
\mathbf{2} \cdot \mathrm{MeOH}\end{array}$ & $\begin{array}{c}{\left[\mathrm{Cu}_{2}(\mu-\mathrm{Cl})_{2}(\text { perbpa })_{2}\right]\left(\mathrm{I}_{3}\right)_{2}} \\
\mathbf{3} \cdot\left(\mathrm{I}_{3}\right)_{2}\end{array}$ \\
\hline Formula & $\mathrm{C}_{33} \mathrm{H}_{25} \mathrm{~N}_{3}$ & $\mathrm{C}_{34} \mathrm{H}_{29} \mathrm{Cl}_{2} \mathrm{CuN}_{3} \mathrm{O}$ & $\mathrm{C}_{66} \mathrm{H}_{50} \mathrm{Cl}_{2} \mathrm{Cu}_{2} \mathrm{I}_{6} \mathrm{~N}_{6}$ \\
\hline Formula weight & 463.56 & 630.07 & 1886.58 \\
\hline Temperature (K) & 293 & 133 & 133 \\
\hline Radiation $(\AA)$ & 0.71073 & 0.71073 & 0.71073 \\
\hline Crystal system & orthorhombic & monoclinic & triclinic \\
\hline$a(\AA)$ & $10.418(1)$ & $8.113(5)$ & $9.838(3)$ \\
\hline$b(\AA)$ & $11.722(1)$ & $25.62(1)$ & $12.685(4)$ \\
\hline$c(\AA)$ & $38.869(4)$ & $13.660(8)$ & $13.191(5)$ \\
\hline$a\left(^{\circ}\right)$ & & & $111.10(3)$ \\
\hline$\beta\left(^{\circ}\right)$ & & $93.40(4)$ & $99.08(3)$ \\
\hline$\gamma\left({ }^{\circ}\right)$ & & & $92.80(3)$ \\
\hline$V\left(\AA^{3}\right)$ & $4746.7(7)$ & 2834(2) & $1506.6(9)$ \\
\hline Space group & $P b n b$ & $P 2_{1} / n$ & $P \overline{1}$ \\
\hline$Z$ & 8 & 4 & 1 \\
\hline$D_{\text {calcd }}\left(\mathrm{g} \mathrm{cm}^{-3}\right)$ & 1.297 & 1.476 & 2.079 \\
\hline$\mu\left(\mathrm{mm}^{-1}\right)$ & 0.076 & 0.993 & 3.918 \\
\hline $\begin{array}{l}\text { Observed } \\
\text { reflections }\end{array}$ & 27820 & 48934 & 29122 \\
\hline $\begin{array}{l}\text { Independent } \\
\text { reflections }\end{array}$ & 3560 & 6441 & 6839 \\
\hline $\begin{array}{l}\text { Number of } \\
\text { parameters }\end{array}$ & 325 & 399 & 395 \\
\hline$R_{1}(I>2 \sigma(I))$ & 0.0767 & 0.07 & 0.064 \\
\hline$w R_{2}$ (all data) & 0.2134 & 0.134 & 0.194 \\
\hline Goodness of fit & 1.014 & 1.01 & 1.284 \\
\hline
\end{tabular}


Table 2. Selected bond distances and angles for $\mathbf{2} \cdot \mathrm{MeOH}$ and $\mathbf{3} \cdot\left(\mathrm{I}_{3}\right)_{2}$.

\begin{tabular}{|c|c|c|c|c|c|}
\hline Bond Distances $(\AA ̊)$ & $\mathbf{2} \cdot \mathrm{MeOH}$ & Bond Angles $\left({ }^{\circ}\right)$ & $\mathbf{2} \cdot \mathrm{MeOH}$ & & \\
\hline $\mathrm{Cu} 1-\mathrm{N} 1$ & $2.007(4)$ & $\mathrm{N} 1-\mathrm{Cu} 1-\mathrm{N} 2$ & $80.7(1)$ & $\mathrm{N} 2-\mathrm{Cu} 1-\mathrm{Cl} 1$ & $163.2(1)$ \\
\hline $\mathrm{Cu} 1-\mathrm{N} 2$ & $2.046(4)$ & $\mathrm{N} 1-\mathrm{Cu} 1-\mathrm{N} 3$ & $160.8(2)$ & $\mathrm{N} 2-\mathrm{Cu} 1-\mathrm{Cl} 2$ & $94.7(1)$ \\
\hline $\mathrm{Cu} 1-\mathrm{N} 3$ & $2.012(4)$ & $\mathrm{N} 1-\mathrm{Cu} 1-\mathrm{Cl} 1$ & $96.8(1)$ & N3-Cu1-Cl1 & $98.0(1)$ \\
\hline $\mathrm{Cu} 1-\mathrm{Cl1}$ & $2.247(1)$ & $\mathrm{N} 1-\mathrm{Cu} 1-\mathrm{Cl} 2$ & $92.3(1)$ & $\mathrm{N} 3-\mathrm{Cu} 1-\mathrm{Cl} 2$ & $96.7(1)$ \\
\hline \multirow[t]{2}{*}{$\mathrm{Cu} 1-\mathrm{Cl} 2$} & $2.592(1)$ & $\mathrm{N} 2-\mathrm{Cu} 1-\mathrm{N} 3$ & $81.7(2)$ & $\mathrm{Cl} 1-\mathrm{Cu} 1-\mathrm{Cl} 2$ & $102.02(4)$ \\
\hline & $\mathbf{3} \cdot\left(\mathrm{I}_{3}\right)_{2}$ & & 3. $\left(\mathrm{I}_{3}\right)_{2}$ & & \\
\hline $\mathrm{Cu} 1-\mathrm{N} 1$ & $2.008(6)$ & $\mathrm{N} 1-\mathrm{Cu} 1-\mathrm{N} 2$ & $81.8(2)$ & $\mathrm{N} 2-\mathrm{Cu} 1-\mathrm{Cl} 1$ & $168.5(1)$ \\
\hline $\mathrm{Cu} 1-\mathrm{N} 2$ & $2.038(4)$ & $\mathrm{N} 1-\mathrm{Cu} 1-\mathrm{N} 3$ & $163.0(2)$ & N2-Cu1-Cl1', & $95.7(1)$ \\
\hline $\mathrm{Cu} 1-\mathrm{N} 3$ & $1.992(6)$ & N1-Cu1-Cl1 & $97.9(1)$ & N3-Cu1-Cl1 & $97.3(1)$ \\
\hline $\mathrm{Cu} 1-\mathrm{Cl1}$ & $2.257(1)$ & $\mathrm{N} 1-\mathrm{Cu} 1-\mathrm{Cl1}$ & 93.7 (1) & N3-Cu1-Cl1', & $92.2(1)$ \\
\hline $\mathrm{Cu} 1-\mathrm{Cl1}$, & $2.643(1)$ & $\mathrm{N} 2-\mathrm{Cu} 1-\mathrm{N} 3$ & $81.8(2)$ & $\mathrm{Cl1}-\mathrm{Cu} 1-\mathrm{Cl} 1$, & $95.71(4)$ \\
\hline
\end{tabular}

Table 3. Oxidation peaks of DPV for $\mathbf{1}$ and $\mathbf{2} \cdot 0.5 \mathrm{H}_{2} \mathrm{O}$

\begin{tabular}{cccc}
\hline$E_{\text {ox }}(\mathrm{V} v s . \mathrm{Ag} / \mathrm{AgCl})$ & & \\
\hline $\mathbf{1}$ & 0.867 & 0.936 & \\
$\mathbf{2} \cdot 0.5 \mathrm{H}_{2} \mathrm{O}$ & & 0.942 & \\
perylene & 0.985 & 1.093 \\
\hline
\end{tabular}


Table S1. Averaged bond lengths ( $a-g)$ of perylene group $(\AA)$ and intraplanar distances $(\delta)$ of perylene groups $(\AA)$

\begin{tabular}{|c|c|c|c|c|c|c|c|}
\hline & $a$ & $b$ & $c$ & $d$ & $e$ & $f$ & $g$ \\
\hline 1 & $1.427(4)$ & $1.416(5)$ & $1.359(5)$ & $1.397(5)$ & $1.378(4)$ & $1.433(4)$ & $1.471(4)$ \\
\hline $2 \cdot \mathrm{MeOH}$ & $1.414(8)$ & $1.391(8)$ & $1.396(9)$ & $1.389(8)$ & $1.401(8)$ & $1.410(8)$ & $1.476(7)$ \\
\hline $\mathbf{3} \cdot\left(\mathrm{I}_{3}\right)_{2}$ & $1.448(7)$ & $1.41(1)$ & $1.38(1)$ & $1.407(8)$ & $1.38(1)$ & $1.43(1)$ & $1.485(7)$ \\
\hline perylene $e^{\text {ref.13 }}$ & $1.424(6)$ & $1.400(8)$ & $1.370(9)$ & $1.418(8)$ & $1.397(7)$ & $1.425(6)$ & $1.471(5)$ \\
\hline & $\delta$ & & & & & & \\
\hline 1 & 3.45 & & & & & & \\
\hline $\mathbf{2} \cdot \mathrm{MeOH}$ & 3.42 & & & & & & \\
\hline $\mathbf{3} \cdot\left(\mathrm{I}_{3}\right)_{2}$ & 3.47 & & & & & & \\
\hline perylene & 3.45 & & & & & & \\
\hline
\end{tabular}

Table S2. Elemental analysis for $\mathbf{3}$

\begin{tabular}{llll}
\hline & $\mathrm{C}(\%)$ & $\mathrm{H}(\%)$ & $\mathrm{N}(\%)$ \\
\hline found & 43.13 & 2.52 & 4.34 \\
calcd for $\left[\mathrm{Cu}_{2} \mathrm{Cl}_{2} \text { (perbpa) }\right]_{2} \mathrm{I}_{5.6}$ & 43.18 & 2.75 & 4.58 \\
calcd for $\left[\mathrm{Cu}_{2} \mathrm{Cl}_{2} \text { (perbpa) }\right]_{2} \mathrm{I}_{6}$ & 42.02 & 2.67 & 4.45 \\
calcd for $\left[\mathrm{Cu}_{2} \mathrm{Cl}_{2} \text { (perbpa) }\right]_{2} \mathrm{I}_{5}$ & 45.05 & 2.86 & 4.78 \\
\hline
\end{tabular}

Table S3. Oxidation peaks $E_{\mathrm{ox}}$ for $1,2 \cdot 0.5 \mathrm{H}_{2} \mathrm{O}$, and perylene in DMF (DPV).

\begin{tabular}{cccc}
\hline$E_{\text {ox }}(\mathrm{V} v s . \mathrm{Ag} / \mathrm{AgCl})$ & & \\
\hline $\mathbf{1}$ & 0.867 & 0.936 & \\
$\mathbf{2} \cdot 0.5 \mathrm{H}_{2} \mathrm{O}$ & & 0.942 & \\
perylene & 0.985 & 1.093 \\
\hline
\end{tabular}



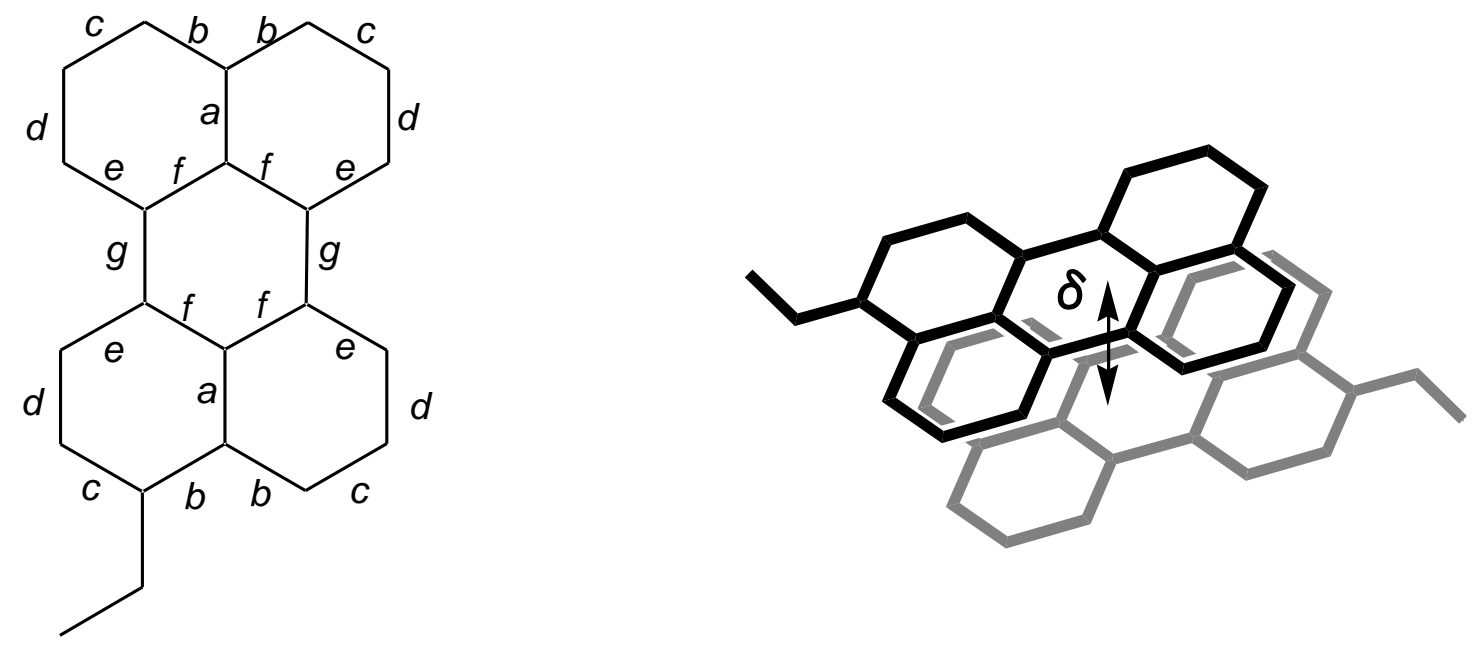

Figure S1. Captions for Table S1 


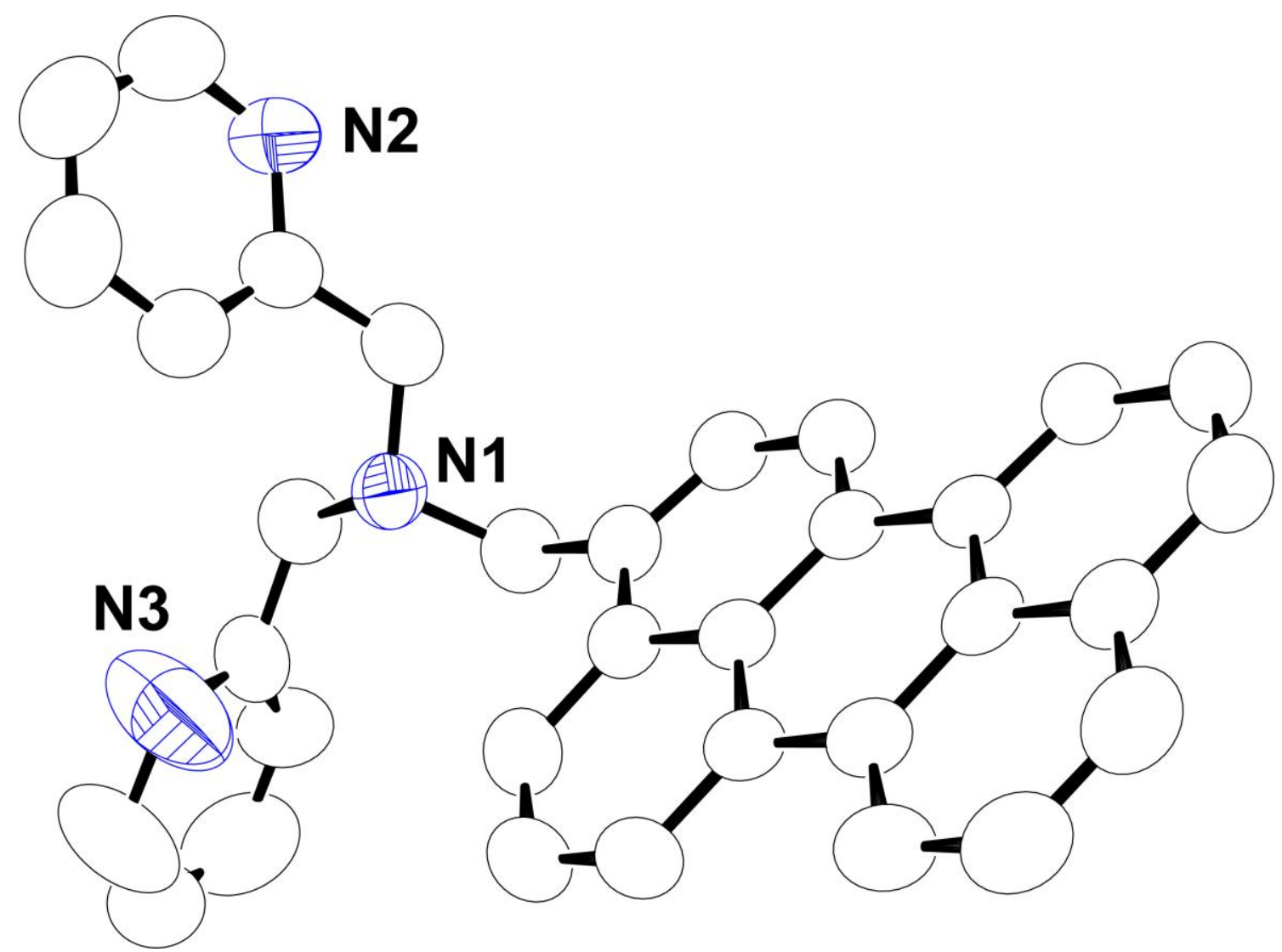

Figure S2. ORTEP view of perbpa (1) with thermal ellipsoids at $50 \%$ probability. Hydrogen atoms are omitted for clarity. 

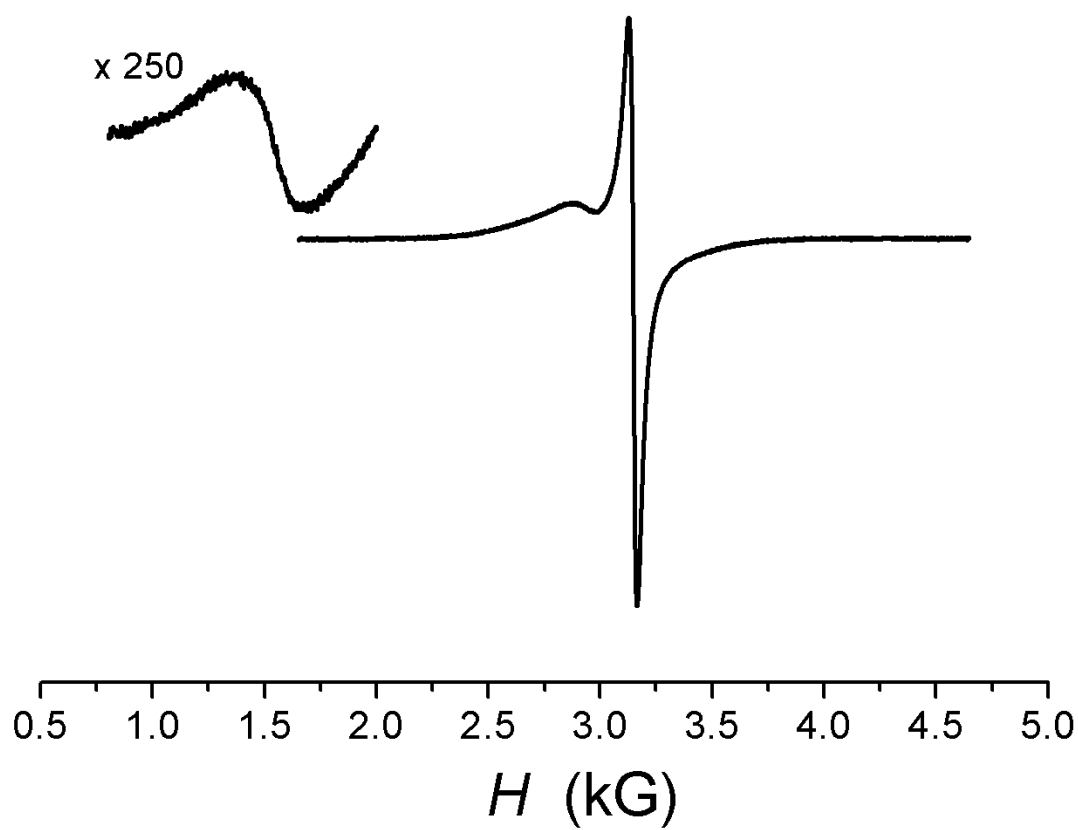

Figure S3. X-band EPR spectra (powder) for $\mathbf{2} \cdot 0.5 \mathrm{H}_{2} \mathrm{O}$ and $\mathbf{3} \cdot \mathrm{I}_{5.6}$ at $4 \mathrm{~K}$. 


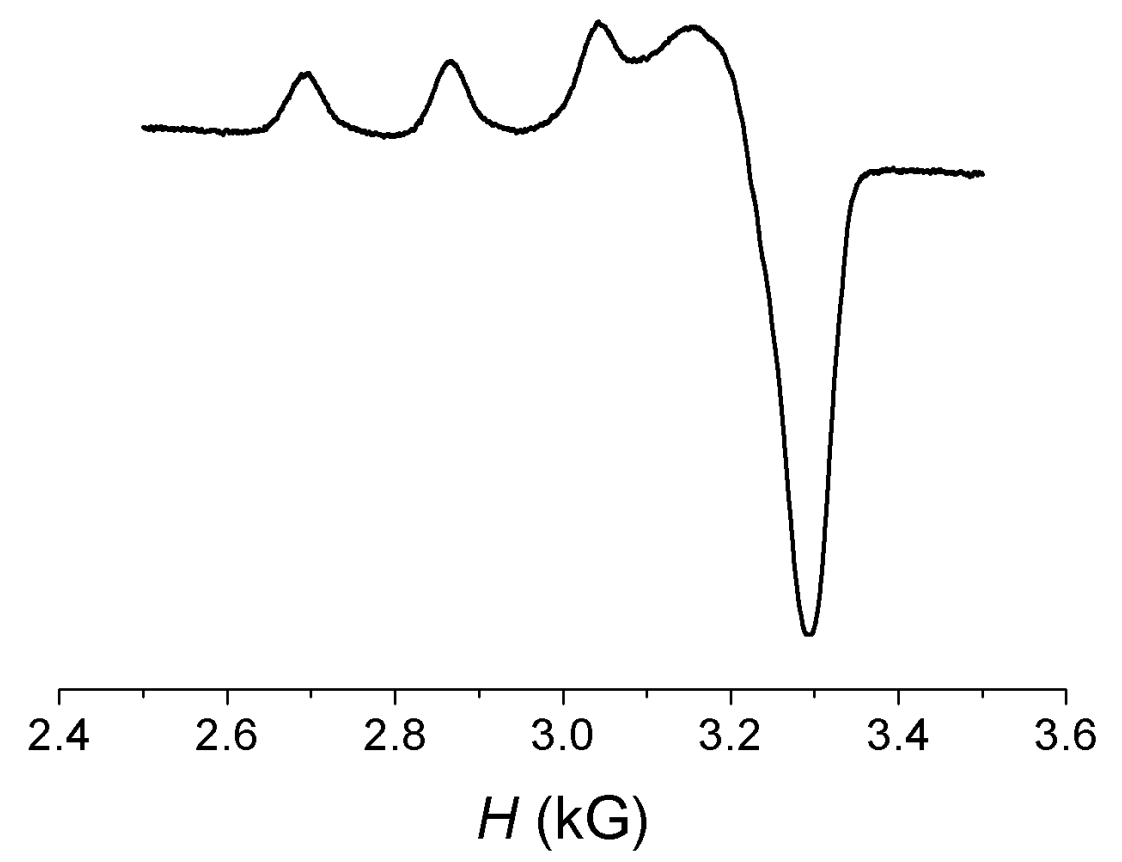

Figure S4. X-band EPR spectrum (frozen DMF solution) for $3 \cdot \mathrm{I}_{5.6}$ at $77 \mathrm{~K}$. 


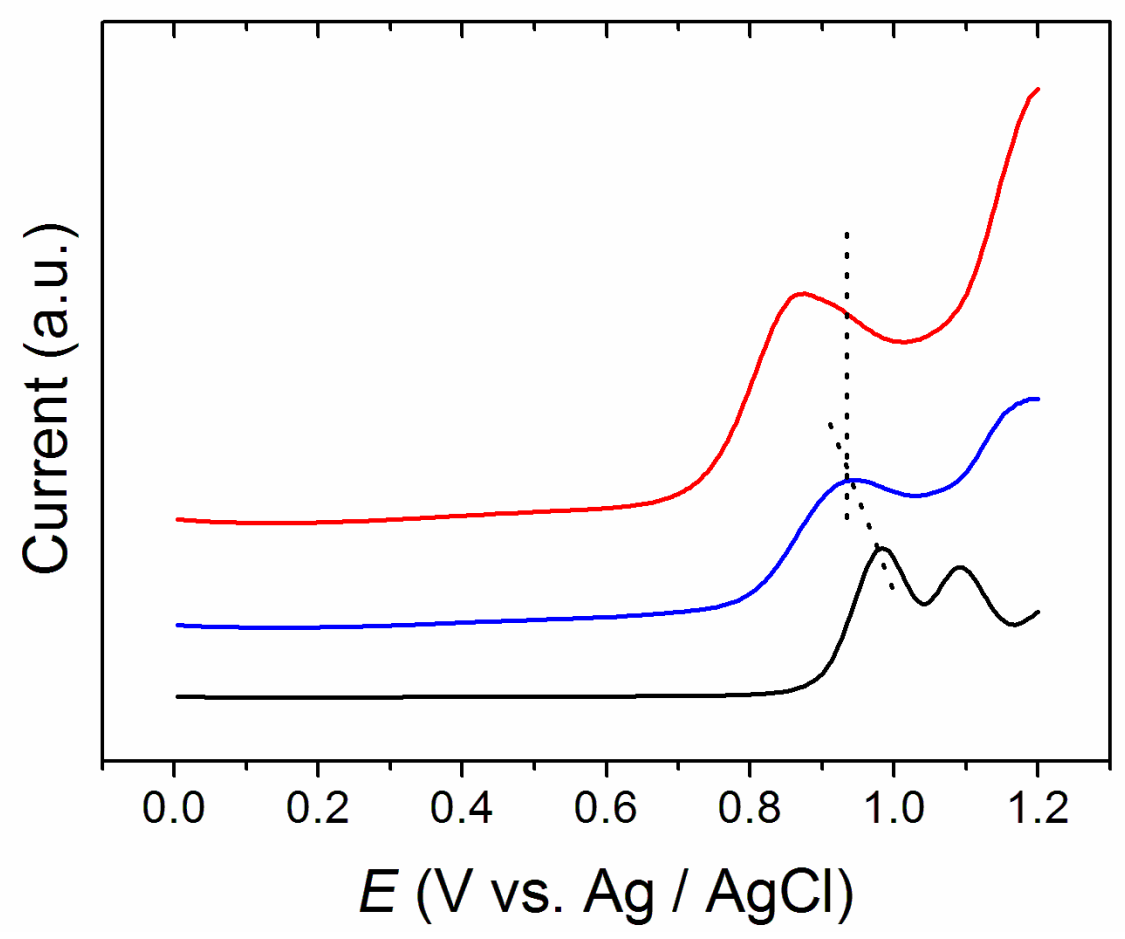

Figure S5. Differential pulse voltammograms for 1 (red), 2 (blue), and perylene (black). Dotted lines represent the oxidation peak of perylene group (see text). 